Empowerment and Nutrition in Niger: Insights from the Women's Empowerment in Nutrition Grid

Erin Lentz, Elizabeth Bageant, and Sudha Narayanan

Indira Gandhi Institute of Development Research, Mumbai December 2019 


\title{
Empowerment and Nutrition in Niger: Insights from the Women's Empowerment in Nutrition Grid
}

\author{
Erin Lentz, Elizabeth Bageant, and Sudha Narayanan
}

Email(corresponding author): sudha@igidr.ac.in

\begin{abstract}
We present a novel application of a regression decomposition technique, the Shapley Owen decomposition, to identify the aspects of empowerment associated with undernutrition in Niger. Niger is one of the poorest countries in the world, and has fared consistently poorly on a range of human development indicators, including women's nutritional status. Nutritional status is the outcome of a complex set of interdependent factors; empowerment too is a multidimensional concept. It is often unclear which policy interventions unequivocally empower women in ways that improve nutritional wellbeing. We aim to identify areas of intervention by categorizing the drivers of nutrition into a series of domains (food, health, fertility and institutions) and empowerment dimensions (knowledge, resources, and agency). We then we predict body mass and anemia based on these domain-dimensions and other controls using Demographic and Health Survey data for Niger. Broadly, we find that access to the domain-dimensions of health resources and fertility resources play a substantial role in nutritional outcomes in Niger. We also consider variations across subpopulations. By identifying the relative contribution of each domain-dimension, our approach offers a unique insight into what sectors are most closely related to the nutritional status of Nigerien women.
\end{abstract}

Keywords: West Africa; nutrition; gender; empowerment; nutrition-sensitive

JEL Code: J16, D13, I00, I3 


\title{
Empowerment and Nutrition in Niger:
}

\section{Insights from the Women's Empowerment in Nutrition Grid}

\author{
Erin Lentz, Elizabeth Bageant, and Sudha Narayanan ${ }^{1}$
}

\footnotetext{
${ }^{1}$ Lentz is an Assistant Professor, Lyndon B Johnson School of Public Affairs, University of Texas at Austin; Bageant is a Research Support Specialist, Cornell University, Ithaca NY; and Narayanan is an Associate Professor, Indira Gandhi Institute for Development Research, Mumbai. Lentz is corresponding author (erinclentz@utexas.edu). The authors appreciate valuable feedback from Chris Barrett, Marc Bellemare, Sarah Eckhoff, Gwenelyn O'Donnell, Joanna Upton, and attendees at a CARE Webinar. The Atkinson Center's Impact for Innovation Fund's Cornell-CARE program generously supported this research. Any remaining errors are our own.
} 


\title{
Empowerment and Nutrition in Niger: Insights from the Women's Empowerment in Nutrition Grid
}

\begin{abstract}
We present a novel application of a regression decomposition technique, the Shapley Owen decomposition, to identify the aspects of empowerment associated with undernutrition in Niger. Niger is one of the poorest countries in the world, and has fared consistently poorly on a range of human development indicators, including women's nutritional status. Nutritional status is the outcome of a complex set of interdependent factors; empowerment too is a multidimensional concept. It is often unclear which policy interventions unequivocally empower women in ways that improve nutritional wellbeing. We aim to identify areas of intervention by categorizing the drivers of nutrition into a series of domains (food, health, fertility and institutions) and empowerment dimensions (knowledge, resources, and agency). We then we predict body mass and anemia based on these domain-dimensions and other controls using Demographic and Health Survey data for Niger. Broadly, we find that access to the domain-dimensions of health resources and fertility resources play a substantial role in nutritional outcomes in Niger. We also consider variations across subpopulations. By identifying the relative contribution of each domain-dimension, our approach offers a unique insight into what sectors are most closely related to the nutritional status of Nigerien women.
\end{abstract}

Keywords: West Africa; nutrition; gender; empowerment; nutrition-sensitive 


\section{Women's Empowerment and Nutrition in Niger: Insights from the Women's Empowerment in Nutrition Grid}

\section{Introduction}

In a number of countries, rates of undernutrition remain alarmingly high. Economic growth alone cannot secure nutritional wellbeing (Haddad et al. 2003; Victora et al. 2008; Vollmer et al. 2014). Researchers have identified a series of other interdependent factors important for children's nutritional status, ranging from food intake and health, to sanitation facilities, parental care practices, access to social programs, and to the empowerment of mothers (UNICEF 1990; Headey et al. 2015; Malapit et al. 2015). While important global efforts have prioritized particular interventions to improve nutritional status (Berhman et al. 2004; Bhutta et al. 2013), we know less about the relative importance of the broader set of interdependent factors for nutritional outcomes. Thus, policymakers aiming to improve nutrition face an expansive set of potential policy levers with little guidance on which factors are most constraining for nutritional outcomes; prioritizing among these factors when selecting policy approaches is critical, particularly for countries with limited budgetary resources (Victora et al. 2008; Behrman et al. 2004).

The selection of policy levers is further complicated because nutritional status is the outcome of a complex set of interdependent factors (UNICEF 1990). One such factor, women's empowerment, could potentially be crucial for nutritional outcomes in resource poor and gender-inequitable settings. Recent research has identified generally positive associations between women's empowerment and children's nutritional status (Pratley 2016). However, findings vary, pointing to the wide variety of empowerment measures used. We also know less about which aspects of empowerment are important for women's nutritional outcomes. As a result, it is unclear which policy interventions empower women in ways that also improve their nutritional wellbeing.

In this paper, we aim to address this gap by presenting findings that highlight the relative importance of various empowerment-related drivers of women's nutrition. We focus on Niger, a country that faces formidable economic constraints and has fared consistently poorly on a range of human 
development indicators, including nutritional outcomes and women's status. Niger is one of the poorest countries in the world, and economic growth remains low. The scope for economic growth to deliver nutritional security is especially limited. Thus, state policies are crucial for supporting nutrition; identifying which policy areas can best support nutrition is especially critical in such resource-poor environments.

In section two, we provide a brief overview of nutrition and wellbeing indicators in Niger, and of efforts to measure women's empowerment. In section three, we introduce the concept of nutritional empowerment, a theory- and research-driven framing we use to understand and categorize the drivers of nutrition in Niger. In section four, we introduce the Shapley-Owen regression decomposition method, a technique that allows us to identify the relative importance of different categories of nutrition drivers. We describe our data in section five. In section six, we present descriptive statistics, and in seven, we present decomposition results that can help to identify the factors that most constrain nutrition. We find strong evidence that health and fertility resources contribute more to women's nutritional outcomes than either improved nutrition knowledge or the ability to make decisions (joint or individual) within the household. We conclude with limitations and policy guidance.

\section{Wellbeing in Niger and role of empowerment for nutrition}

Niger, a landlocked country in West Africa, has made important strides. Between 1992 and 2012, several factors crucial for wellbeing have improved, including halving the infant mortality rate and mortality rate for children under age five, and doubling the number of pregnant women using a health facility for delivery (DHS 2019). Yet, Niger has the worst multidimensional poverty index score in the world, with 89 percent of population living below the multidimensional poverty line (UNDP 2019).

Niger has not yet made the same progress on addressing undernutrition that it has with child mortality. There has been limited movement in the past two decades on key nutrition indicators. Estimates from the most recently available Demographic and Health Survey (DHS), collected in 2012, show that 43 percent of children under the age of five were stunted (i.e., had low height-for-age), an indicator of 
chronic malnourishment, down three percent from 1992 (DHS 2019). Similarly, the 18.5 percent of children under five were wasted (i.e., had low weight-for-height) in 1992, and this figure dropped by only half a percent by 2012. Children under age five also face alarming rates of anemia: 73 percent. These high rates of undernutrition are compounded by poverty, climate change, and recent conflict (USAID 2018).

Recently, nutrition has garnered increasing attention from state actors in Niger. In 2011, Niger released the Initiative 3N, (Niger Ministry of Agriculture 2011), "Nigeriens Nourishing Nigeriens.” In 2016, it released its 2016-2025 National Nutrition Security Policy (PNSN), defining roles and responsibilities across ministries to support nutrition (Republique du Niger 2016). However, resources for implementation remain limited (Kovalenko and Szabo 2016). The 2018 Scaling Up Nutrition (SUN) country profile for Niger reports that the PNSN has not yet been adopted and that "a lack of common medium-term objectives and a clear specification make it impossible to synergise reflections, actions and advocacy..." (SUN 2018. P.1). Whether efforts such as Initiative 3N and PNSN will result in substantial improvements in nutritional outcomes remains an open question (Mercy Corps 2016; SUN 2018).

One hypothesized reason why undernourishment of children remains high in many places such as Niger is that their mothers face unmet nutritional needs themselves. When women are unable to access and utilize the nutrients they need, it can have lasting consequences for themselves and for their children (Victora et al. 2008; Almond and Currie 2011). Nutritional insults during the first thousand days - from a woman's pregnancy to her child's second birthday-can have a significant impact on the wellbeing of children (Victora et al. 2008; Almond and Currie 2011).

Further, women's nutritional status matters not only for children's outcomes, but also in its own right (United Nations Sustainable Development Goals (SDG) I and V). Women face deep gender inequities in Niger as well as low literacy rates and high fertility rates, all of which can hinder their abilities to achieve adequate nutrition for themselves and their families. The literacy rate for women of reproductive age is just 14 percent, and only 12 percent of married women are using a modern form of contraception. Niger's fertility rate is among the highest in the world with 7.6 births per woman (UNDP 2019) and many women begin having children while they themselves are young. The adolescent birth rate 
is 207 births per 1000 women aged 15-19 (UNDP 2019). Anemia rates for women of reproductive age (15-49) are 45 percent (WFP 2019), consistent with Stevens et al. (2013) finding that West and East Africa likely have the highest prevalence of anemia worldwide. These realities contribute to Niger being ranked as $175^{\text {th }}$ out of 179 countries in Save the Children's 2015 Mother's Index (Save the Children 2015; USAID 2018).

Being empowered may help women to navigate barriers to adequate nutrition for themselves and their children. For example, Na et al. (2015) examine the relationship between women's empowerment and infant and young child feeding (IYCF) in multiple countries, including Niger, finding positive associations between empowerment dimensions (economic, legal, socio-familial) and healthy IYCF practices. Beyond Niger, numerous studies have identified a positive association between women's empowerment and the nutritional outcomes of their children (see Cunningham et al. 2014 and Pratley 2016 for reviews).

Among the fewer studies focusing on the relationship between women's empowerment and women's own nutrition, results are more mixed (Cunningham 2014; Kadiyala et al. 2014; Sraboni et al. 2014; Malapit and Quisumbing 2015; Malapit et al. 2015). A major difficulty in drawing lessons from empowerment-related research is that outcomes and subpopulations vary across studies, limiting comparability across findings. Also problematic is the lack of consensus on the best way to capture empowerment through data. For example, Pratley (2016), in a review of empowerment's role in health and nutrition outcomes, identifies 121 unique empowerment-related indicators in use.

Another reason for the lack of consistency across results is that some studies rely on fit-forpurpose data, while others use widely available secondary data sources, including Demographic and Health Surveys. The DHS has extensive cross-country coverage and detailed information on health and nutrition outcomes for women and their children. The DHS also has an empowerment module and details on health seeking behavior and household resources. For these reasons and its availability for many countries, the DHS surveys are heavily used by researchers aiming to understand linkages between women's empowerment and nutrition (e.g., Ewerling et al. 2017; Miedema et al. 2018; Ballon 2018; 
Hanmer and Klugman 2015; Upadhyay and Karasek 2012). Yet, the focus of the DHS is on demographic and health outcomes; it has limited coverage of economic indicators, such as detailed information on income, and consumption. Its coverage of assets, and in particular agricultural assets, is also limited, potentially leading to bias in wealth measures. Nonetheless, the richness of the nutritional data for all adult women ages 15-49 make it unique when many other surveys focus on nutritional outcomes of children only, or children and their mothers.

Researchers using the DHS operationalize empowerment in several ways. One approach is to incorporate a narrow set of relevant variables available in the DHS based on indicators used in prior studies or broad notions of women's empowerment. Ewerling et al. (2017) develop the SWPER (Surveybased Women's Empowerment) index based on 15 indicators related to women's empowerment. The authors use data reduction techniques to find three SWPER domains, including attitude toward domestic violence; social independence (e.g., level of education, age at birth of first child; and frequency of reading a newspaper, among others); and involvement in household-level decision and working outside the home. Their study sample includes only women in a union, and their analysis excludes important variables, such as the ability to access contraception. Yet, marital status and control over reproduction are likely key drivers of both empowerment and nutrition/health outcomes. A second approach is to use a larger set of empowerment measures that correspond to a specific theoretical framing of empowerment. Miedema et al. (2018), for example, draw on the work of Naila Kabeer (1999) to identify 39 indicators related to three domains of empowerment: enabling conditions, such as education, and wage work; intrinsic agency, such as attitudes around domestic violence; and instrumental agency, such as participation in household decisions. The authors also employ data reduction techniques to select indicators to reflect each domain. They find that these domains operate consistently across East Africa.

Similar to Miedema et al. (2018), we use a theoretically informed approach, also drawing on the work of Kabeer to identify a set of categories, which we refer to as "domain-dimensions", related to empowerment. Our specific effort is to identify aspects of empowerment that are salient to nutritional outcomes, as opposed to a general notion of empowerment. Because women can experience different 
degrees of empowerment in different spheres (e.g., in agricultural production versus in nutrition) (Kabeer 1999; Lentz et al. 2019), we focus on the concept of nutritional empowerment to understand how empowerment in each nutrition-related domain-dimension influences nutritional outcomes. We also take a broad perspective on what indicators may be relevant for nutritional empowerment. While we are similarly limited by the DHS data in some of the ways described above, we include fertility measures, women both in and not in unions, and we do not seek to reduce the number of variables to identify a smaller set of factors associated with empowerment. Rather, we are interested in how informative the domain-dimensions are for nutritional outcomes.

\section{Nutritional empowerment}

We define nutritional empowerment as the process by which individuals acquire the capacity to be well fed and healthy, in a context where this capacity was previously denied to them (Authors 2017). This process entails acquiring knowledge about, and a say over, nutritional and health practices; gaining access to and control over intake of adequate and nutritious food; and being able to draw support from both family and other institutions to secure and maintain an adequate diet and health. Our approach is in contrast to studies and policy interests that discuss women's empowerment and health/nutritional status in low-income countries as important primarily for child outcomes. We explicitly acknowledge the intrinsic value of healthy, empowered women, whether they are mothers or not (see Authors 2017).

\subsection{Women's Empowerment in Nutrition (WEN) Grid}

To measure nutritional empowerment, we foreground the role of women's empowerment in nutritional outcomes for women. We combined insights from the UNICEF conceptual framework for maternal and child nutrition (1990, 2018) (Figure 1) with insights from the empowerment literature (Kabeer 1999) and field work in South Asia on barriers to nutrition faced by women and their families (Authors 2017).

Figure 1 presents UNICEF's widely adopted framework for nutritional outcomes. UNICEF categorizes drivers of nutrition as immediate causes; underlying causes; and basic causes. To adjust this framework to 
be relevant for adults, we exclude the immediate cause of inadequate care, which refers to care practices for children, such as breastfeeding. The WEN grid contains four "domains": food, health, institutions, and fertility. The underlying causes of undernutrition include inadequate household food security and an unhealthy household environment, which we refer to as food and health domains. We incorporate both paid and unpaid work into these two domains, as work influences undernutrition via its effects on health and food intake and requirements. For example, working for an income or being engaged in food production can allow women to access more and better food but work also involves energy expenditure. We then include UNICEF's basic causes in our institutional domain, which contains formal and informal institutions and norms that influence nutrition. Finally, we explicitly add the fertility domain, which is particularly relevant for women of childbearing age.

While there are numerous ways to conceptualize empowerment, many researchers rely on Naila Kabeer's (1999) conceptualization (Alkire et al. 2013; Ballon 2018; Miedema et al. 2018). Kabeer defines empowerment as "the process by which those who have been denied the ability to make strategic life choices acquire such an ability" (p. 435). Kabeer outlines three dimensions that support the expansion of choice: resources, agency, and achievements. A simple example of how these dimensions support empowerment is that having agency without resources limits the transformative aspects of agency. Further, having resources and agency may not be empowering if a woman cannot achieve her outcome of interest (in this case nutrition). Departing from Kabeer, we also include knowledge, which is a component of resources under Kabeer's theory, as a fourth dimension. Knowledge plays a key role in nutritional outcomes (Spronk et al. 2014) and behavior change communication is a common policy intervention. For these reasons, we think knowledge about nutrition merits specific attention. We treat nutritional outcomes as the achievement against which we measure the relative importance of the nutritional domains and empowerment dimensions.

Figure 2 presents the WEN grid. The columns in Figure 2 are dimensions of empowerment: knowledge, resources, agency and achievements (Kabeer 1999; Alkire et al. 2013). These dimensions are each applied to nutritionally relevant domains of food, health, and fertility (UNICEF 1990), which are 
rows in Figure 2. We consider institutions as cross-cutting, because institutions are basic causes that encompass a variety of contextual factors, such as norms and social contexts, that influence and shape resources, agency, knowledge, and achievements. Therefore, we do not apply Kabeer's empowerment dimensions to the institutions domain. We then use the domain-dimensions to systematically identify how each of the ten domain-dimensions influences nutritional achievements of women of reproductive age.

The domain-dimensions can be inter-related. For example, lack of adequate health resources can limit the effectiveness of knowledge about how to use health resources. More concretely, drawing from findings in South Asia, women may understand that open defecation can harm their nutrition, but without adequate funds to build pit latrines, they have little recourse (Authors 2017). See Authors (2017) for a detailed explanation of each domain-dimension and their associated indicators. While initially designed for women in South Asia, our operationalization of empowerment is intentionally broad, incorporating a wide-range of drivers of nutrition, in order to be useful in a range of contexts.

We combine WEN grid with a regression-based decomposition method (described below) to apportion the total explained variation (R-squared) in women's nutrition outcomes to different domaindimensions. This decomposition helps clarify which sectoral strategies are most likely to result in improved nutritional outcomes for women. For example, expanding access to clean water, sanitation and health services is associated with reductions in child mortality in Niger and elsewhere (IMF 2017; Bhutta et al. 2013; Headey et al. 2015; Larsen et al. 2017). However, a substantial component of systematic policy efforts in Niger have focused on either food aid in response to emergencies and disasters or expanding food resources through investments in agriculture to develop resilience (IMF 2017). All of these efforts potentially impact women's nutrition, but it is unclear if, among these, interventions in some domains (food, health, fertility and institutions) and dimensions (expansion of resources, improving knowledge or strengthening women's agency) are more closely related to nutrition outcomes than others. The Shapley-Owen decomposition technique, while it cannot establish causality, identifies the contribution of a domain-dimension by assessing contribution of domain-dimension elements in explaining variation in the nutritional outcome. A higher value indicates that a domain-dimension 
contributes to more of the explained variation in nutritional outcomes. It also helps us point to which domain-dimensions are shared constraints across sub-populations or regions and identify potential areas where interventions would need to be differentiated based on target regions or groups.

\section{Data}

The 2012 Niger DHS interviews women of aged 15-49 within each sampled household and are representative of this population at both the district and national level (DHS 2019). We use the term "women" to refer to these respondents. A limitation of the DHS is that it does not sample older women or girls between the ages of 5 and 15. These populations may have different outcomes. Given high rates of adolescent marriage, girls below the age of 15 may be particularly vulnerable and remains an important sub-population for future research. The data, collected during March - July 2012, are anonymized and institutional review board approval was not required for this study.

To populate our WEN grid, we categorize relevant variables from the DHS into each domaindimension. Drawing on evidence from the existing literature and our theoretical framework, we categorized 124 indicators included in the DHS survey. We then use the 10 domain-dimensions in our regression decomposition, where each domain-dimension is a vector of unique indicators. We estimate the proportion of the total explained variance in nutritional outcomes attributable to each domaindimension. Table 1, discussed below, provides key DHS indicators included in the WEN grid. See Table A1.1 in the supplementary materials (SM) for a comprehensive list of indicators and Authors (2017) for a detailed discussion on how indicators are categorized in a specific domain-dimension.

Our nutritional outcomes for women of reproductive age include body mass index (BMI) and an indicator variable for anemia status. A woman is considered underweight, an indicator of malnutrition, when her BMI (weight in kilograms divided by height in meters-squared) is below 18.5. About 4.5 percent of our sample (232 women out of 5118 women with BMI measures) have a BMI of 30 or above and are obese based on the World Health Organization's (WHO) standard cutoff. Drivers of and policy responses to obesity differ from those of undernutrition; therefore we exclude obese individuals from our 
BMI sample. A woman is anemic $(=0)$ when her hemoglobin level falls below WHO hemoglobin standards, which vary by pregnancy status. In our anemia status estimations, we include indicators for tobacco use and obesity, both of which can influence hemoglobin levels (Cepeda-Lopez et al. 2010).

\section{Method: Shapley-Owen decompositions}

The Shapley-Owen decomposition is a technique to apportion the explained variation (R-squared) across domain-dimensions. The decomposition estimates ten Shapley-Owen values: one for each domaindimension. These values indicate how much of the total explained variation in nutritional status within the sample is explained by each domain-dimension. Each Shapley-Owen value is obtained by estimating a large number of models where each covariate of interest appears along with exhaustive permutations of all other covariates. Each permutation is run with the covariate of interest and without it. The difference in R-squared between models with and without the covariate of interest is averaged over the exhaustive set of regressions. This average is the contribution of the covariate of interest to R-squared (see Narayanan et al. 2019, for a detailed discussion on the Shapley-Owen approach). In other words, the difference in R-squared from the complete set of models that include and exclude the covariate of interest is averaged to estimate the contribution of the covariate of interest to total R-squared. A useful mathematical attribute of Shapley-Owen decompositions is that they are aggregation consistent, meaning the total proportion of the explained R-squared is the simple sum of each covariate. An implication is that we can aggregate across covariates within domain-dimensions to identify which domain-dimensions of nutritional empowerment matter most for nutritional status, and we can also identify which factors within a specific domain dimensions are the most important.

Shapley Owen decomposition techniques have a distinct advantage over regression in situations where there is high collinearity between variables in a model (Mishra 2016). Shapley-Owen decomposition accounts for the collinearity between variables, capturing the total contribution of a given variable despite collinearity. As a result, we can assess the contributions of many variables, some of which are highly collinear; this is less easily done with other approaches. A single regression analysis, for 
example, captures the contribution of a given variable conditional on all other covariates, regardless of the relationships between covariates. When covariates that represent empowerment are highly correlated with one another, their respective regression coefficients might appear insignificant. However, it could be that the relative contribution of that family of correlated factors to explaining variation in the outcome is high. The Shapley-Owen approach, by estimating a series of models and taking their average, is able to account for this (Narayanan et al. 2019)

The base models we run are a series of linear regressions of nutritional achievement, $Y$, on the various subsets of WEN grid covariates, grouped by domain-dimensions, and controls. Equation 1 shows the complete model, including all covariates. We use an indicator variable for the anemia outcome $(1=$ not anemic; $0=$ mild, moderate or severe anemia), and we estimate a linear probability model. For the continuous BMI variable, we estimate a series of ordinary least squares regression models.

$$
\begin{aligned}
Y= & \delta_{0}+\delta_{1} K_{f}+\delta_{2} R_{f}+\delta_{3} A_{f}+\delta_{4} K_{h}+\delta_{5} R_{h}+\delta_{6} A_{h}+\delta_{7} K_{r}+\delta_{8} R_{F e r t}+\delta_{9} A_{r}+\delta_{10} I+ \\
& \delta_{11} X+e
\end{aligned}
$$

In this model, $K, R$ and $A$ refer to vectors representing dimensions of Knowledge $(K)$, Resource $(R)$ and Agency $(A)$. The subscripts $f, h$ and $r$ refer to domains of Food, Health and Fertility, respectively. Each of these is a vector of variables that potentially interact with one another to jointly explain the variation in the outcome. These interactions could be both across variables or factors within a domaindimension or straddling variables across different domain-dimensions. We include a vector of institutional variables $(I)$, and a set of other controls $(X)$, including respondent's pregnancy status, number of months pregnant, marital status, age, age-squared, literacy, educational attainment, partner's educational attainment, household sex ratio, dependency ratio, dependency ratio by gender, exposure to shocks, floor material, wall material, roofing material, interview month, and the DHS wealth index. We also include a control to account for any chronic illnesses that respondents report experiencing in the twelve months prior to the survey. Chronic illnesses hinder the absorption of nutrients, impacting BMI 
and anemia. They may also act as obstacles that hinder the translation of nutritional empowerment. We note that several of these illnesses could result from inadequate pre- or postnatal care, including back pain, renal insufficiency, urinary infections, and abdominal pain. Other chronic illnesses included are: hypertension, cardiac disease, cancer, palsy, asthma, chronic bronchitis, ulcer, headache, thalassemia, vertigo, and others.

Given Niger's high rates of adolescent marriage and pregnancy, and poor maternal health conditions overall, we look beyond aggregate outcomes consider drivers of nutritional outcomes for women ages 20 and older relative to women ages $15-19$. The leading cause of death globally among girls aged 15-19 are pregnancy and childbirth complications (WHO 2018). Further, those residing in urban areas may have easier access to health facilities, to greater diversity of foods, and to information, potentially reflecting urban bias in development policies (Lipton, 1977). As of 2017, an estimated 84 percent of Nigeriens reside in rural areas and we therefore consider whether the influence of different domain-dimensions varies by urban and rural residency. The wealth index, constructed by the DHS, is comprised of information on household ownership of assets, housing materials, and types of sanitation and water access; it also generates relative ranking wealth indices for the rural population and for the urban population. When we compute Shapley-Owen decompositions for urban and rural residents, we include the urban and rural asset indices, respectively. In other decompositions, we use the Niger-wide asset index.

Regional fixed effects are common in other studies of nutritional outcomes (e.g., Headey et al. 2015), but we opt to exclude these. Given that we are not proposing causal identification of specific parameters, such controls can mask important differences that are more actionable from a policy standpoint. Rather, we opt to report a rich set of controls. We do, however, compute region-specific decompositions to understand drivers of variation across the eight regions of Niger (including Niamey as a distinct region).

A limitation of our application of the WEN grid to DHS data is that DHS surveys are designed to measure demographic and health outcomes and do not comprehensively cover the factors informing either 
nutritional and health outcomes or women's empowerment. As a result, the DHS does not fully cover each domain-dimension within the WEN grid (see Table A2.1 in the SM for a comprehensive list of possible candidate indicators). For example, in the DHS survey, there no questions related to food knowledge and we cannot speak to the importance of this domain-dimension for women's nutritional outcomes. However, there is adequate coverage for the other domain-dimensions. A further limitation of the DHS in a diverse agro-ecological context such as Niger is that it combines agricultural, agro-pastoral, and pastoral livelihoods into one occupation code, preventing disaggregation by livelihood group. Constraints to nutritional empowerment may vary with livelihood strategy and mobility.

These limitations aside, the DHS remains valuable given its wide availability, and its collection of nutrition outcomes. Using the DHS, we can identify whether variation across the populated domaindimensions differs meaningfully across geographic locations and age-groups. Thus, our objective is to understand how women's empowerment, inasmuch as it is represented in the DHS survey, influences nutritional outcomes while recognizing that the DHS measures do not fully capture all attributes of women's nutritional empowerment.

In Table 1, we organize key variables from the DHS into each domain-dimension of the WEN grid. We start with 124 indicators in the aggregate anemia regressions and 123 in the BMI regressions (we exclude obese women in the BMI regressions). In our analysis, we include all relevant indicators because we are interested in learning as much as we can about nutritional empowerment and how it relates to nutritional outcomes. Below, we include a robustness check to show that the number of relevant indicators within each domain-dimension do not influence our findings.

\section{Descriptive statistics}

In Table 2, we include an illustrative subset of indicators for each domain-dimension of the WEN grid, including disaggregation by age and residential status. Note that not all questions were fielded to all respondents. For example, in the fertility domain, many items are not relevant for women who are not 
sexually active or who have not had a child. These women's responses are coded as not-applicable ("NA") and are treated as a separate category in our Shapley-Owen decompositions and in our descriptive statistics. Descriptive statistics for all indicators used in the Shapley-Owen decompositions for Niger are presented in the Table A1.1 of the SM. Complete descriptive statistics by region, by urban-rural status, and by age are available upon request.

\subsection{Outcomes:}

Our two nutritional outcomes are anemia and BMI. The estimation samples for BMI and anemia are not identical; we exclude obese women from our BMI estimates and for some respondents BMI is reported but not anemia, or vice versa. The mean BMI for the Niger sample is 21.7, which falls within the healthy weight range of 18.5 and 24.9. About 14 percent of the sampled women are underweight $(\mathrm{BMI}<18.5)$. The prevalence of anemia is much higher. Across samples, between 43 and 45 percent of women have mild, moderate or severe anemia.

\subsection{Health and Fertility Knowledge:}

Indicators that assess women's understanding of issues relevant to the health and fertility domains are "knowledge" indicators. As noted above, the DHS does not include indicators directly relevant to food knowledge. Health knowledge includes indicators such as how to use oral rehydration (ORS) for diarrheal diseases, knowledge of sexually transmitted diseases, and knowledge of AIDS. Overall, we find knowledge rates regarding health to be high. Between 81 and 96 percent of individuals have heard of AIDS, with similar rates aware of sexually transmitted diseases, and between 77 and 93 percent having heard of ORS. Fertility knowledge is more uneven. Between 74 and 94 percent of women know of a modern method of family planning but only about 20 percent of respondents know when ovulation occurs. Further, there is variation between subgroups. For example, about 21 percent of women aged 20 and above know when ovulation occurs compared to only 11 percent for women and girls under age 20 . 


\subsection{Resources:}

The food resources domain-dimension includes indicators for resources than can (1) support own agricultural production and preparation of food, including access to and ownership of agricultural land, ownership of livestock, a pump for irrigation, a refrigerator, and an oven for cooking; and (2) resources that indicate wealth and income that can support purchasing food, including ownership of a home, being self-employed, working seasonally, and working in the past year. We find that about 17 percent of women own their own land and 23 percent of women are employed. For the vast majority of women in a union, their partners are working, although about 12 percent of women in our main sample are not in a union.

Health resources include indicators such as access to improved/treated water sources, and improved toilets, transportation to health centers, and funds to pay for health treatment. Health resources include time spent collecting water and time spent collecting firewood. Spending more time doing these labor-intensive tasks could harm women's nutritional status through high energy expenditures. We find that in urban areas 58 percent of women do not spend time collecting water. In rural areas, the percentage drops to three percent. Older women are more likely to spend longer collecting water than younger women. WASH standards are better in urban areas versus rural areas: about 75 percent versus 8 percent have access to an improved toilet and 77 percent versus 43 percent use soap to clean hands, respectively.

Fertility resources include indicators that capture the quality of pre and postnatal care. Most women are mothers of young children, with only 32 percent of women not having given birth in the past five years or not having begun childbearing. While 57 percent of women received antenatal care, only 30 percent received a post-delivery checkup. Women in urban areas are more likely to have a check-up compared to rural women (39 percent versus 27 percent), but are less likely to receive iron tablets or a tetanus vaccination during pregnancy. More pregnant women received iron pills and vitamin A supplements than a tetanus vaccination while pregnant.

\subsection{Agency:}


Agency-relevant indicators capture women's abilities to make choices. Food agency questions focus on women's abilities to participate in economic decisions and seek employment. Less than 3 percent of women decide alone on major household purchases. Fertility-related agency is limited, despite most women having some knowledge about contraception, again with variation between subgroups. Close to 40 percent of urban women report that they cannot refuse sex, that they feel unsure whether they can or that it depends. The rate for rural women is 63 percent. Of the rural sample, 73 percent report being unable to or unsure whether they can ask a partner to use a condom compared to 43 percent in urban areas. Regarding health agency, 75 percent of women have no problem seeking treatment at a health facility alone. Less than 10 percent of women know how to get a condom; the rate is $18-19$ percent for women in the urban sample, compared to about 5 percent for rural residents. Regarding food agency, 70 percent of urban women report that a partner is never justified in beating a woman who burns food while cooking, compared to 54 percent of rural women.

\subsection{Institutions:}

Institutions include norms (e.g., the experience of domestic violence), and access to sources of general information (e.g., listening to the radio). Some indicators (e.g., owning a phone) capture both access to information and wealth. Differences between urban and rural respondents are most striking. In urban areas 74 percent of women listen to a radio compared to about 57 percent in rural areas. In urban areas, 49 percent of women believe that domestic violence is never justified, compared to 38 percent in rural areas.

\section{Results of Shapley-Owen decomposition for Niger}

We first decompose the WEN grid to the domain-dimension level using Shapley-Owen techniques to identify which sectoral aspects of nutritional empowerment matter most. Before discussing the role of institutions, we ask if the domain-dimensions identified at the aggregate level for Niger are similar for different sub-populations and regions. This approach assists in understanding if the problem of women's nutrition in Niger demands a differentiated or targeted approach. We also decompose the results by 
indicators and rank their importance within each domain-dimension, discussing only those indicators that emerge most strikingly across or between outcomes or subgroups. To close this section, we compute a series of robustness checks.

\subsection{Aggregate findings for Niger}

The WEN grid variables and controls together explain 23 percent of the total variation in BMI, and about 11 percent for anemia. Table 3 presents the percentage contribution by each domain-dimension to the Rsquared. The percent contributions of the 9 domain-dimensions and 1 set of control variables sum to 100

percent. Our R-squared values for BMI are on par with other studies of nutritional outcomes; models used by Headey et al. to assess children's stunting in Bangladesh had R-squared values of approximately 25 percent (2015). A 2012 study combined DHS and water availability data to estimate anemia in Mali had an R-squared of 13 percent, which is slightly better than our model but which also incorporates satellite imagery (Jankowska et al. 2012). Overall, the explained variation in anemia models are lower than for BMI because the DHS omits numerous health-related factors that contribute to anemia in particular. For example, infections and parasites can contribute to low hemoglobin levels (Agoya et al. 2006); inadequate food intake, malaria, sickle-cell disorders and thalassaemias also matter for hemoglobin levels (Stevens et al., 2013) as does indoor air pollution from unclean cook stoves (Kyu et al. 2010). Further, models that predict dichotomous outcomes (i.e., anemic or not), typically explain less variance than models for continuous outcomes.

In our aggregate models, controls explain 27 and 29 percent of the total explained variation in BMI and anemia, respectively. Put differently, our WEN grid domain-dimensions explain 73 and 71 percent of the total explained variation in these nutritional outcomes. The vector of controls do not lend themselves to change via policy interventions as much as factors identified in the WEN grid do. For this reason, we focus our discussion on WEN grid domain-dimensions.

Our results in Table 3 indicate that the WEN grid's resources dimension, particularly in fertility and health domains, contribute more to women's BMI and anemia status than either knowledge or 
agency. WEN grid resources explain nearly 41 percent of the R-squared for BMI, with fertility resources the most important (18 percent), followed by health (11.5 percent) and food (11.5 percent). For anemia status, the results mirror the BMI results: controls explain 29 percent while the resources dimension explains 42 percent of explained anemia variation. Across resources, health resources (19 percent) and fertility resources (16 percent) play a larger role relative to food resources (6 percent).

The types and relative contribution of resources that support adequate hemoglobin and BMI differ slightly. For both outcomes, fertility resources, such as access to pre and postnatal care and family planning, matter. Food resources contribute twice as much to explaining the variation in undernutrition relative to anemia. This reflects BMI's closer relationship with food intake than anemia. For anemia, access to health resources, which include use of mosquito nets as malaria prevention, and health assets, such as acess to toilets, contribute to the explained variation in hemoglobin levels.

Health knowledge matters more for anemia than for BMI, explaining approximately 11 percent of the total explained variation in anemia and only 6 percent for BMI. The health knowledge indicators, which include understanding of HIV transmission and oral rehydration therapy, capture a basic understanding of biology. This knowledge might help respondents recognize the value of specific vitamins and minerals and of how to stay healthy, both of which could decrease the likelihood of anemia but may be less important in addressing BMI, which people may more readily recognize as resulting from illness or poor quality dietary intake.

The overwhelming contribution of the resource dimension of empowerment in explaining the variation in women's nutritional outcomes suggests that food-forward nutrition interventions or activities that are geared specifically toward addressing women's agency or knowledge around food and nutrition may be less effective than interventions expanding health and fertility resources available to women. The Shapley-Owen decompositions for specific sub-samples mirror the decomposition for the full sample.

\subsection{Age sub-group decompositions}


Figures 3 and 4 compare the aggregate Niger results shown numerically in Table 3, with results disaggregated by age and urban or rural residence. The y-axis is the R-squared value, which is the sum of stacked domain-dimensions and controls. We explain more variation in nutritional outcomes for younger than for older women: 37 percent of the total variation in BMI and 27 percent in anemia for younger women compared to 21 percent of the total variation in BMI and 12 percent of anemia for older women.

For younger and older women's BMI, the proportional contributions of the resource domaindimensions are very closely aligned, contributing 47 percent of the explained variation for younger women and 46 percent for older women. Within the total resource contributions, health resources and fertility resources contribute 16-23 percent of the explained variation and food resources contribute 8-10 percent for both age groups. The contribution of fertility resources is slightly lower for younger women (16 percent) than for older women (20 percent), possibly reflecting that about half of women under age 20 and 8 percent of woman aged 20 and above are not sexually active.

For anemia, we see a few differences between older and younger women that we do not see in the BMI results. For younger women, the anemia results resemble the BMI results, with key contributors to explaining the variation in anemia being health resources ( 25 percent), fertility resources (18 percent) and food resources ( 8 percent). For older women, health resources (16 percent) and fertility resources (20 percent) are key contributors; health knowledge (10 percent) appears more important for older women than younger women. While literacy and education are included as controls in the models, older women may still see greater returns to understanding of fundamental health concepts relative to younger women.

\subsection{Urban and rural decompositions}

Our model better predicts variation in nutritional outcomes for urban Niger than for rural Niger (39 and 19 percent for BMI and anemia, respectively, as against 21 and 13 percent in rural areas). However, the contributions of each domain-dimension for both urban and rural nutritional outcomes are quite similar.

As in the aggregate and age-specific analyses, resources within the WEN grid provide the largest share of the explained variation in urban BMI (42 percent) and rural BMI (44 percent). Within resources, 
fertility resources contribute the largest shares with nearly 20 percent for both urban and rural analyses and health resources contribute 11 percent for urban and 14 percent for rural.

Food resources matter more for BMI than for anemia. For anemia, the combined contribution of resources to total explained variation in BMI is 46 and 45 percent for urban and rural areas, respectively. There is a strong, consistent contribution from fertility resources (18-20 percent) and health resources (18-21 percent) across urban and rural women. Health knowledge plays a stronger role for urban women (12 percent) than food resources ( 8 percent). For rural women, health knowledge ( 8 percent) is also more important than food resources ( 6 percent), but the difference is less pronounced.

While agency dimensions contribute relative little explanatory power, there is some variation: fertility agency, which includes the ability to ask a partner to use a condom, having a say in family planning, and the ability to refuse sex, matters for BMI for urban residents more than for rural residents $(8$ percent versus 3 percent of the total R-squared values).

\subsection{Regional decompositions}

There are 7 regions in Niger and DHS includes Niamey, the capital city and major urban center, as a distinct region. Across regions, the DHS estimation sample sizes range from 252 in Agadez, in the remote northeast of Niger, to 801 in Maradi, along the southern border with Nigeria. For BMI, we explain the most variation in Agadez, as seen in Table 4 and Figure 5. We explain the most variation in anemia in Diffa, near Lake Chad, and Agadez, seen in Table 4 Figure 6. These high R-squareds are likely due to the small sample size relative to the large number of total indicators; a larger sample could yield a lower Rsquared value. As with other domain-dimension analyses, we consider the proportion of R-squared explained and rankings of importance. Consistent with the other findings, the Shapley-Owen decompositions indicate that health resources and fertility resources are the primary domain-dimensions within the WEN grid that contribute to variation in anemia and BMI. Across regions, health-resources contribute from around 12 percent of explained variation in BMI in Agadez to about 22 percent in Zinder, also on the border with Nigeria. Across regions, health knowledge explains more variation in the anemia 
findings than in the BMI findings.

\subsection{Institutions}

Institutions, in general, matter less for anemia than for BMI. Regional variation indicates that institutions in Agadez and Diffa play a greater role in explaining the variation in BMI than in other regions (the contributions to explained R-squared are 19 and 23 percent, respectively, relative to an average of about 10 percent for other regions). In both of these regions, few people own assets such as televisions or telephones or have a bank account. These indicators can influence nutrition in at least two ways. Having a bank account indicates one's ability to have some degree of financial autonomy and also indicates having enough surplus to merit having an account. Similarly, owning a phone, a computer, or radio provides a valuable source of information, but also indicates wealth.

\subsection{Decompositions within each domain-dimension}

A consistent finding from our decomposition exercise is that resources matter most and often matter much more than either agency or knowledge. In general, health and fertility resources make the largest contribution to improving nutrition. Our conceptualization of health and nutritional resources include both community attributes (e.g., travel time and costs to use health services) and household attributes (e.g., soap for handwashing, improved toilets, and distance to water sources). These sorts of indicators may warrant further consideration as possible policy targets.

Applying the Shapley-Owen decomposition technique to variables within each domain-dimension of the aggregate Niger findings, we find that time spent collecting water is one of key indicators within the health-resources domain that explains variation in BMI (and anemia outcomes). Spending more than an hour daily to collect water is associated with worse nutritional outcomes. In our BMI sample, 82 percent of respondents spend more than an hour collecting water each day. For the anemia sample, the percent of respondents is 81 . This specific resource seems to matter for all the decompositions, although with some variation. Decomposing findings by age, we find that the time spent collecting water is much more important for older women's BMI outcomes than for anemia outcomes of older women or either 
nutritional outcome for younger women. Future research could help us to understand the mechanism: for example, decreased time collecting water could decrease energy expenditures, or there may be additional unaccounted for factors simultaneously driving the burden of carrying water and older women's BMI outcomes.

We also find that access to improved toilets (versus open defecation) is a health resource that seems to matter for both BMI and anemia and across all decompositions. This finding is consistent with literature that indicates that poor sanitation can lead to greater illnesses and diseases, including parasites, which can contribute to anemia (Larsen et al. 2017). Only 26 percent of women in the BMI sample report having access to an improved toilet (27 percent for anemia). Access to improved toilets seems to matter more to rural anemia outcomes than urban anemia outcomes, suggesting the value of improved rural WASH facilities within households. In rural areas, 8 percent of residents have an improved toilet, compared to 78 percent of urban residents. In both rural and urban outcomes, use of soap or ash for hand cleaning, not using tobacco, and access to clean water sources matter for anemia, again consistent with other studies (Kyu et al. 2010; Cepeda-Lopez et al. 2010; Larsen et al. 2017).

The fertility resources indicators that are important for explaining the variation in BMI are also important for anemia, and are similar for both the urban and rural anemia subsamples. Access to family planning methods from a healthcare facility and using family planning methods, one's most recent birth being in a healthcare facility, and receiving a post-natal check-up are important health resources. In both rural and urban areas, access to antenatal and postnatal check-ups, iron pills, and vitamin A supplements are all important contributors and relate to the quality and accessibility of fertility care. These point to the value of high-quality health systems and fertility care for women, perhaps especially those in the reproductive age. These variations suggest that while there are some natural candidates for broad-based policy action (e.g., access to quality pre and postnatal care), targeting specific groups might call for specific focus areas (e.g., WASH in rural areas). On the flip-side, some interventions, such as expanding access to clean water, might have differential impacts by subpopulation by, for example, supporting older women's nutritional status by reducing their drudgery. 
Do the Shapley-Owen decompositions also point to the need for geographically differentiated policy? For the regional decompositions, there is some variation, although the majority of indicators that matter most are consistent with the aggregate findings. The factors that are most prominent within health resources in Maradi and Zinder do differ from those in Agadez. In Maradi about 20 percent of women and in Zinder about 27 percent have improved toilets, compared to 56 percent of women in Agadez. In Agadez, 41 percent of women report spending less than one hour collecting water or not collecting water at all, while only 12 percent and 13 percent report the same in Zinder and Maradi, respectively. Thus, addressing WASH needs in regions lagging behind could support improved nutritional outcomes.

\subsection{Robustness checks}

The first of our four robustness checks assesses the appropriateness of the linear probability model for the binary anemia outcome by re-estimating using logistic regression. Logistic regression results and the linear probability model results are highly similar. The predicted values from both estimation approaches are highly correlated with a Pearson's correlation coefficient of 0.994 (see Figure A3.1 in the SM). The linear probability model offers a more tractable approach to the Shapley-Owen decomposition, particularly for the disaggregated analysis with smaller sample sizes, and for this reason, we present these as our main results.

Second, we assess whether a continuous anemia outcome performs differently than the binary option by estimating the complete set of results using a continuous hemoglobin level outcome variable rather than a binary outcome variable. The key difference between the binary anemia status results and the continuous hemoglobin results is that, as expected, we are able to explain a higher proportion of variation in the continuous hemoglobin variable. The share of variation explained by each domaindimension remains consistent regardless of which outcome we use. See SM Figure A3.2.

Third, we investigate how the normative nature of allocating indicators by WEN grid domaindimension may affect results. The number of indicators in each domain-dimension differs, and domaindimensions with more indicators tend to contribute more to the explained variation than domain- 
dimensions with fewer indicators. To assess whether the contribution of each domain-dimension is sensitive to the number of indicators we apply two different data-driven approaches to selecting indicators. First, we exclude all indicators that contribute less than one percent of explained variation. Second, we set a cut-off of ten for the number of indicators included in each domain-dimension. Our findings are qualitative similar across different indicator selection approaches, with resources consistently the most important domain of nutritional empowerment. For BMI, results are virtually identical regardless of which indicator selection approach we use. For anemia status, the most important domain dimensions remain health and fertility resources and health and fertility knowledge, but their rankings vary by approach. Figure A3.3 in the SM illustrates these three approaches side-by-side for the aggregate Niger results. Disaggregated results for these alternative approaches are available upon request.

Finally, we assess whether the net effect of a given domain-dimension is different from zero, based on "improvements" of one standard deviation in indicators within a given domain dimension. We do this by standardizing all explanatory variables so they have a mean of 0 and a standard deviation of 1 . We then estimate model (1) and test the whether the linear sum of coefficients within the given domain dimension is equal to zero. These results are displayed in Figures A3.4, A3.5 and Table A3.1. Of note, we see a particularly large relationship between health resources and BMI, with a statistically significant 1.4 unit increase in BMI per standard deviation increase in health resources. This is in contrast to a insignificant relationship between BMI and a one SD change either in health agency or in health knowledge. We see the same insignificance of a one SD change in health agency and health knowledge for anemia. We also see a statistically significant 7.7 percent decrease in the probability of anemia associated with fertility agency and a 10 percent decrease for fertility knowledge. These results underscore the importance of health resources, particularly for BMI.

\section{Discussion: Policy implications and Limitations}

Relying on income growth alone to support nutrition may not deliver and countries with limited resources and great needs, such as Niger, face a range of possible nutrition-sensitive and nutrition-specific policy 
levers. Some of these are well recognized. The African Development Bank's (2018) Niger country strategy, for example, focuses on addressing the high risk and low productivity in the agricultural sector, which exposes Niger to food insecurity and its large agriculture-dependent population to poverty, particularly the most vulnerable groups (young people and women). There is limited existing evidence with respect to other interventions aimed at improving nutritional outcomes (Fenn et al. 2015; Hoddinott et al. 2014; Langendorf et al. 2014). How to prioritize among existing interventions is not immediately clear.

Nutritional empowerment provides a normative framework that aims to comprehensively identify the barriers and opportunities women face in achieving adequate nutrition. The food, health, fertility and institutions domains of nutrition and knowledge, resources, and agency dimensions of empowerment provide a means by which we can classify the wide variety policy levers into domain-dimension groups that constitute nutritional empowerment. The Shapley-Owen decomposition technique, combined with this framing of nutritional empowerment, identifies focal points within the WEN grid that most explain the variations in women's nutritional outcomes and that can support women's nutritional empowerment.

Our findings suggest that there are critical areas of intervention that can support women's nutritional empowerment across Niger. One consistent policy implication from our results is that among numerous nutrition-sensitive interventions, those that expand women's access to health, fertility, and food resources have the potential to be most transformative. This is intuitive. In the absence of resources, possessing nutritional knowledge or agentive empowerment might not translate into better nutritional outcomes. A woman with health-related knowledge and the agency to make health decisions may still experience barriers to adequate service delivery from the supply side that limit her nutritional status. Further, our results indicate that supporting expansion of these household-level WASH-based resources, decreasing time spent collecting water, and expanding access to and use of health facilities and pre and postnatal care could support reductions in anemia and improvements to BMI.

One tentative policy implication is that programs focusing on trainings and knowledge dispersal may have less impact relative to expanding service provision. However, our decomposition of results by 
age and by urban-rural residents indicate the need for nuance. Health knowledge is still valuable, particularly for older women. More research is needed to understand why health knowledge benefits older women more: it could reflect their greater agency to act on acquired knowledge relative to younger women or indicate the value of filling knowledge gaps among those less exposed to health and nutrition specific education. As more young women attend school, they may be able to gain basic literacy and knowledge that can support their ability to make choices to enhance their nutrition, making health knowledge less of a barrier to nutritional outcomes. Controls, which consistently matter for both BMI and anemia outcomes, are, by their nature, much harder to address from a policy-perspective. Our work suggests improvements in controls such as education and wealth could also impact nutritional outcomes. Nonetheless, these variables likely require longer timeframes than improving access to health facilities or expanding reach of pre and postnatal care.

Applying a Shapley-Owen decomposition to nutrition data in the DHS is useful first step, but relying on existing data substantially narrows the scope of the analysis. Fit-for-purpose data could incorporate the domain-dimension of food knowledge, richer measures of wealth and income, and more information on intermediate outcomes, such as dietary diversity, allowing us to speak to their importance in nutritional outcomes. Further, fit-for-purpose data could allow for Niger-relevant decompositions. For example, analysis by livelihood and agro-ecological zone is not supported by DHS data but could identify the value of policies targeted to these subgroups.

Finally, the results presented here are not causal, but are associative and reflect the Shapley-Owen approach which allows for interdependencies among indicators. As a result, we cannot definitively identify which indicators within domain-dimensions are most important with this technique. Additional qualitative and or quantitative work could help identify which factors within a domain-dimension are most useful to address and further explore specific impact pathways. We believe, nonetheless, that by ranking the contributions of each domain-dimension, we can support policymakers seeking to identify which domains and which dimensions of nutritional empowerment merit more focused analysis and discussion. 


\section{References:}

Agoya, M. A., Spiekermann-Brouwer, G. M., Traore, A. K., Stoltzfus, R. J., and Garza, C. 2006. "Determinants of anemia in pregnant women in Mali." Food and Nutrition Bulletin. 27(1): 3-11

African Development Bank (2018) Niger: Country Strategy Paper 2018-22, RDGW/CONE, October 2018.

Alkire, S., Meinzen-Dick, R., Peterman, A., Quisumbing, A. R., Seymour, G., \& Vaz, A. (2013). The Women's Empowerment in Agriculture Index. World Development, 52, 71-91.

http://doi.org/10.1016/j.worlddev.2013.06.007

Almond, D. and Currie, J. 2011. "Killing me softly: The fetal origins hypothesis." Journal of Economic Perspectives. 25 (3): 153-172

Ballon, P. 2018. "A structural equation model of female empowerment." The Journal of Development Studies. 54(8): 1303-1320.

Behrman, J.R., Alderman, H., \& Hoddinott, J. 2004. "Hunger and Malnutrition.” Copenhagen Consensus - Challenges and Opportunities. February 19.

Bhutta, Z.A. et al. 2013. "Evidence-Based Interventions for Improvement of Maternal and Child Nutrition: What Can Be Done at What Cost?” The Lancet. 382(9890): 452-477.

Cepeda-Lopez, AC, Aberli, I. \& Zimmerman MB. 2010. "Does obesity increase risk for iron deficiency? A review of the literature and the potential mechanisms." International Journal for Vitamin and Nutrition Research. 80(4-5):263-70.

Cunningham, K., Ruel, M., Ferguson, E., \& Uauy, R. 2014. "Women's empowerment and child nutritional status in South Asia: a synthesis of the literature." Maternal \& Child Nutrition, 11(1), 1-19. http://doi.org/10.1111/mcn.12125

Demographic and Health Survey. 2019. "Where we work: Niger." Accessed April 16, 2019. https://dhsprogram.com/Where-We-Work/CountryMain.cfm?ctry id $=29 \& c=$ Niger\&Country $=$ Niger\&cn $=\& r=1$

Ewerling, F., Lynch, J. W., Victora, C. G., van Eerdewijk, A., Tyszler, M. and Barros, A. J. D. 2017. "The SWPER index for women's empowerment in Africa: development and validation of an index based on survey data." September. The Lancet Global Health. S: e916-23.

Fenn, B., Noura, G., Sibson, V. Dolan, C. and Shoham, J. 2015. "The Role of Unconditional Cash Transfers during a Nutritional Emergency in Maradi Region, Niger: A Pre-Post Intervention Observational Study." Public Health Nutrition 18.02: 343-51. 
Haddad, L., Alderman, H., Appleton, S., Song, L. and Yohannes, Y., 2003. Reducing child malnutrition: How far does income growth take us?. The World Bank Economic Review, 17(1), pp.107-131.

Hanmer, L. and Klugman, J. 2015. “Exploring women's agency and empowerment in developing countries: where do we stand?" Feminist Economics: 1 - 27.

Headey, D. Hoddinott, J., Ali, D., Tesfaye, R., and Dereje, M. 2015. "The other Asian enigma: Explaining the rapid reduction of undernutrition in Bangladesh." World Development. 66: 749-751.

Hoddinott, J., Sandström, S. and Upton, J. 2014. The Impact of Cash and Food Transfers: Evidence from a Randomized Intervention in Niger. IFPRI Discussion Paper 01341. International Food Policy Research Institute, Washington, DC.

IMF. 2017. "Niger Selected Issues". IMF Country Report No. 17/60. https://www.imf.org/en/Publications/CR/Issues/2017/02/24/Niger-Selected-Issues-44705

Jankowska, M.M., Lopez-Carr, D., Funk, C., Husak, G.J., and Chafe, Z. A. "Climate change and human health: spatial modeling of water availablity, malnutrition, and livelihoods in Mali, Africa." Applied Geography. 33:415.

Kabeer, N. 1999. Resources, agency, achievements: Reflections on the measurement of women's empowerment. Development and Change.

Kadiyala, S., Harris, J., Headey, D., Yosef, S., and Gillepsie, S. 2014. "Agriculture and nutrition in India: mapping evidence to pathways." Annals of the New York Academy of Sciences. 1-14.

Kovalenko, D. and Szabo, S., 2016. "Poor infrastructure and lack of employment opportunities contribute to high malnutrition rates in Niger." SUN Newsletter. Accessed April 19, 2019.

https://scalingupnutrition.org/news/fighting-malnutrition-in-niger-improving-planning-and-budgeting-toensure-an-integrated-approach/

Kyu, H. H., Georgiades, K. and Boyle, M. 2010. "Biofuel smoke and childhood anemia in 29 countries: A multilevel analysis." Annals of Epidemiology. 20(11): 811-817.

Langendorf, C., Roederer, T., de Pee, S., Brown, D., Doyon, S., Mamaty, A.A., Touré, L.W.M., Manzo, M.L. and Grais, R.F., 2014. Preventing acute malnutrition among young children in crises: a prospective intervention study in Niger. PLoS medicine, 11(9), p.e1001714.

Larsen, D., Grisham, T., Slawsky, E., and Narine, L. 2017. “An individual-level meta-analysis assessing the impact of community-level sanitation access on child stunting, anemia, and diarrhea: Evidence from DHS and MICS surveys." Plos: Neglected Tropical Diseases.

https://doi.org/10.1371/journal.pntd.0005591 
Lentz, E.C., Narayanan, S., and De, Anuradha. 2019. "Last and least: Findings on intrahousehold undernutrition from participatory research in South Asia." Social Science and Medicine. 232:316-323. https://doi.org/10.1016/j.socscimed.2019.05.024

Lipton, 1977. Why poor people stay poor: a study of urban bias in world development. Australia National University Press: Canberra.

Malapit, H. J. L., Kadiyala, S., Quisumbing, A. R., Cunningham, K., \& Tyagi, P. 2015. Women's Empowerment Mitigates the Negative Effects of Low Production Diversity on Maternal and Child Nutrition in Nepal. Journal of Development Studies, 51(8), 1097-1123.

http://doi.org/10.1080/00220388.2015.1018904

Malapit, H.J.L., \& Quisumbing, A.R. 2015. "What dimensions of women's empowerment in agriculture matter for nutrition in Ghana?" Food Policy, 52, 54-63.

Mercy Corps, 2016. "Niger Strategic Resilience Assessment: Final Report." Accessed April 2, 2019. https://www.mercycorps.org/sites/default/files/Niger\%20STRESS\%20Report English.pdf ;

Miedema, S.S., Haardorfer, R., Webb Girard, A. and Yount, K. 2018. "Women's empowerment in East Africa: Development of a cross-country comparable measure.” World Development. 110: 453-464.

Mishra, S.K., 2016. Shapley Value Regression and the Resolution of Multicollinearity. Journal of Economics Bibliography, 3(3), 498-515.

Na, M., Jennings, L., Talegawkar, S. A., \& Ahmed, S. 2015. Association between women's empowerment and infant and child feeding practices in sub-Saharan Africa: an analysis of Demographic and Health Surveys. Public Health Nutrition, 18(17), 3155-3165.

http://doi.org/10.1017/S1368980015002621

Narayanan, S., Rathore, U. and Sharma, M. 2019. "IGIDR working paper: Women's nutritional empowerment and their well-being: Identifying key drivers in India and Bangladesh." Accessed April 22, 2019. http://www.igidr.ac.in/igidr-working-paper-15/

Niger Ministry of Agriculture, 3N Initiative: Les Nigériens Nourrissent les Nigériens, Republic of Niger, August 2011. http://extwprlegs1.fao.org/docs/pdf/ner145888.pdf

Niger, Republique du. 2016. "Politique Nationale de Securite Nutritionelle au Niger (2016-2025)." Accessed April 2, 2019. http://extwprlegs1.fao.org/docs/pdf/ner173472.pdf

Pratley, P. 2016. Associations between quantitative measures of women's empowerment and access to care and health status for mothers and their children: A systematic review of evidence from the developing world. Social Science \& Medicine, 169, 119-131.

http://doi.org/10.1016/j.socscimed.2016.08.001 
Save the Children. 2015. State of the World's Mothers Report 2015: The Urban Disadvantage (pp. 1-80). Save the Children Federation.

Spronk, I., Kullen, C., Burdon, C., and O’Connor, H. 2014. "Relationship between nutrition knowledge and dietary intake." British Journal of Nutrition. 111: 1713-1726

Sraboni, E., Malapit, H. J., Quisumbing, A., and Ahmed, A. 2014. "Women's empowerment in agriculture: What role for food security in Bangladesh." 2014. World Development. 61(11-52).

Stevens, G. A., et al. 2013. "Global, regional, and national trends in haemoglobin concentration and prevalence of total and severe anaemia in children and pregnant and non-pregnant women for 1995-2011: a systematic analysis of population-representative data." Lancet: Global Health. 1(1): e16-e25.

SUN (Scaling up Nutrition). 2019. "Niger Country Profile.” Accessed April 9, 2019. https://scalingupnutrition.org/wp-content/themes/elision/pdf/SUNPR2018/SUN_Report_EN_2018_Country_Niger.pdf

UNDP. 2016. "Human Development Report: 2016.” Accessed April 16, 2019. http://hdr.undp.org/en/2016-report

UNDP. 2019. Human Development Data (1990-2017). Accessed January 18, 2019. http://hdr.undp.org/en/data.

UNICEF. 1990. 'Strategy for Improved Nutrition of Children and Women in Developing Countries.' Policy Review Paper E/ICEF/1990/1.6, JC 27 UNICEF /WHO. UNICEF: New York.

UNICEF. 2018. 'Training: UNICEF Conceptual Framework.’ P4. Accessed 21 May 2018. http://unicef.org/nutrition/training/2.5/4.html

UN SDGs. 2019. "Sustainable Development Goals Knowledge Platform.” Visited July 2, 2019. https://sustainabledevelopment.un.org/?menu=1300

Upadhyay, Ushma D. and Deborah Karasek. 2012. "Women's Empowerment and Achievement of Desired Fertility in Sub-Saharan Africa." International Perspectives on Sexual and Reproductive Health. 38(2):78-89.

USAID. 2018. "Niger: Nutrition Profile.” Accessed January 18, 2019. https:/www.usaid.gov/sites/default/files/documents/1864/Niger-Nutrition-Profile-Mar2018-508.pdf.

Victora C.G., et al. 2008. "Maternal and child undernutrition: consequences for adult health and human capital." Lancet. 371: 340-357.

Vollmer, S. et al. 2014. "Association between economic growth and early childhood undernutrition: evidence from 121 Demographic and Health Surveys from 36 low-income and middle-income countries" The Lancet Global Health, Volume 2, Issue 4, Pages e225 - e234, April. 
WFP. 2019. “Country Brief: Niger” Accessed April 16, 2019. https://www1.wfp.org/countries/niger

World Health Organization (WHO). 2018. "Adolescent Pregnancy.” February 23. Accessed April 9, 2019. https://www.who.int/news-room/fact-sheets/detail/adolescent-pregnancy

Yount, K., A. Peterman, A., and Cheong, Y.F. 2018. "Measuring women's empowerment: A need for context and caution." The Lancet Global Health. 6(1), e29. 
Table 1: Applying the WEN grid to DHS Niger variables (adapted from Authors)

\begin{tabular}{|c|c|c|c|}
\hline Domain & Knowledge & Resources (the means) & $\begin{array}{l}\text { Agency (executive and } \\
\text { implementation) }\end{array}$ \\
\hline \multirow{3}{*}{ Food } & \multirow[t]{3}{*}{ NA } & $\begin{array}{l}\text { Self-employed, paid work, } \\
\text { seasonal work }\end{array}$ & $\begin{array}{l}\text { Decision-making on spending own } \\
\text { earnings or husband's earnings }\end{array}$ \\
\hline & & Ownership of land and livestock & Domestic violence is not justified \\
\hline & & $\begin{array}{l}\text { Spousal employment status } \\
\text { Own assets including refrigerator, } \\
\text { oven, water pump }\end{array}$ & $\begin{array}{l}\text { Final say on making large household } \\
\text { purchases }\end{array}$ \\
\hline \multirow{7}{*}{ Health } & \multirow{7}{*}{$\begin{array}{l}\text { Heard of ORS, } \\
\text { STI, AIDs, } \\
\text { aquatabs, fistula. } \\
\text { Transmission of } \\
\text { HIV; where to get } \\
\text { an HIV test }\end{array}$} & $\begin{array}{l}\text { Water source for drinking and } \\
\text { cooking, treatment of water, use } \\
\text { of soap }\end{array}$ & $\begin{array}{l}\text { Respondent can get a condom; } \\
\text { justified to request condom use if } \\
\text { partner has STI }\end{array}$ \\
\hline & & $\begin{array}{l}\text { Cooking (fuel, separate kitchen, } \\
\text { stove type) }\end{array}$ & Final say on own healthcare \\
\hline & & $\begin{array}{l}\text { Unpaid work (fetching water, } \\
\text { fuel) }\end{array}$ & $\begin{array}{l}\text { Can visit health facility alone. Does } \\
\text { not need permission }\end{array}$ \\
\hline & & Mosquito net use & \\
\hline & & Toilet type, number of users, etc. & \\
\hline & & \multirow{2}{*}{\multicolumn{2}{|c|}{$\begin{array}{l}\text { Access to health care, responsiveness, timeliness, etc. } \\
\text { Health insurance } \\
\text { Has bicycle, plow, motorcycle, automobile } \\
\text { Dependency ratio }\end{array}$}} \\
\hline & & & \\
\hline Fertility & $\begin{array}{l}\text { Awareness on } \\
\text { getting pregnant, } \\
\text { contraception and } \\
\text { access to } \\
\text { contraception } \\
\text { Knowledge of } \\
\text { NGO condom use } \\
\text { campaign (Foula } \\
\text { condoms) } \\
\text { Participated in } \\
\text { literacy } \\
\text { programme }\end{array}$ & $\begin{array}{l}\text { Access to knowledge, sources of } \\
\text { information on accessing family } \\
\text { planning (e.g., radio, health } \\
\text { worker, clinics) } \\
\text { Reasons for not accessing } \\
\text { contraception } \\
\text { Antenatal care (place, regularity, } \\
\text { Postnatal care } \\
\text { Immunization (tetanus), IFA, } \\
\text { prophylactics for parasites, } \\
\text { malaria, fansidar, vitamin A } \\
\text { Delivery location }\end{array}$ & $\begin{array}{l}\text { Decision on use of contraception, on } \\
\text { the use of condoms } \\
\text { Can refuse sex } \\
\text { Beliefs about female circumcision } \\
\text { Reason for not using contraception } \\
\text { e of services) }\end{array}$ \\
\hline Institutions & $\begin{array}{l}\text { Exposure to newsp } \\
\text { Has electricity, cor } \\
\text { Has bank and savir } \\
\text { Final say on visits } \\
\text { Involvement in dec } \\
\text { Married before bir }\end{array}$ & $\begin{array}{l}\text { per, radio, TV, movies } \\
\text { puter, phone } \\
\text { gs account } \\
\text { o family or relatives } \\
\text { sion regarding own marry } \\
\text { of first child }\end{array}$ & \\
\hline
\end{tabular}


Table 2: Selected descriptive statistics by nutritional outcome and subgroup

\begin{tabular}{|c|c|c|c|c|c|c|c|c|c|c|}
\hline & \multicolumn{5}{|c|}{ BMI Mean Values } & \multicolumn{5}{|c|}{ Anemia Mean Values } \\
\hline & $\begin{array}{l}\text { Aggregate } \\
\mathrm{n}=4236 \\
\end{array}$ & $\begin{array}{l}\text { Rural } \\
\mathrm{n}=3153 \\
\end{array}$ & $\begin{array}{l}\text { Urban } \\
\mathrm{n}=1083 \\
\end{array}$ & $\begin{array}{r}<20 \\
\mathrm{n}=768 \\
\end{array}$ & $\begin{aligned} & \mathbf{2 0}+ \\
& \mathrm{n}= 3468 \\
&\end{aligned}$ & $\begin{array}{l}\text { Aggregate } \\
\mathrm{n}=4326 \\
\end{array}$ & $\begin{array}{l}\text { Rural } \\
\mathrm{n}=3133 \\
\end{array}$ & $\begin{array}{c}\text { Urban } \\
\mathrm{n}= \\
1183 \\
\end{array}$ & $\begin{array}{r}<\mathbf{2 0} \\
\mathrm{n}=728 \\
\end{array}$ & $\begin{aligned} \mathbf{2 0 +} \\
\mathrm{n}=3577 \\
\end{aligned}$ \\
\hline $\begin{array}{l}\text { Outcomes } \\
\text { Any anemia (mild, moderate, severe) (BMI Sample is } \\
4118 \text { ) } \\
\text { Respondent BMI }\end{array}$ & $\begin{array}{r}55 \% \\
21.71\end{array}$ & $\begin{array}{r}54 \% \\
21.39\end{array}$ & $\begin{array}{r}56 \% \\
22.66\end{array}$ & $\begin{array}{r}55 \% \\
20.12\end{array}$ & $\begin{array}{r}55 \% \\
22.06\end{array}$ & $\begin{array}{r}55 \% \\
22.30\end{array}$ & $\begin{array}{r}55 \% \\
21.62\end{array}$ & $\begin{array}{r}57 \% \\
24.10 \\
\end{array}$ & $\begin{array}{r}55 \% \\
20.33\end{array}$ & $\begin{array}{r}55 \% \\
22.72\end{array}$ \\
\hline $\begin{array}{l}\text { Controls } \\
\text { Woman's age in years } \\
\text { Resp free of chronic disease } \\
\text { No education } \\
\text { Pregnant } \\
\text { Walls: cement/stone/wood/brick/block }\end{array}$ & $\begin{array}{r}28.42 \\
83 \% \\
77 \% \\
14 \% \\
12 \% \\
\end{array}$ & $\begin{array}{r}28.89 \\
87 \% \\
88 \% \\
15 \% \\
2 \% \\
\end{array}$ & $\begin{array}{r}27.04 \\
72 \% \\
45 \% \\
9 \% \\
42 \% \\
\end{array}$ & $\begin{array}{r}16.90 \\
89 \% \\
53 \% \\
11 \% \\
16 \% \\
\end{array}$ & $\begin{array}{r}30.97 \\
82 \% \\
82 \% \\
14 \% \\
11 \% \\
\end{array}$ & $\begin{array}{r}28.68 \\
82 \% \\
76 \% \\
14 \% \\
13 \% \\
\end{array}$ & $\begin{array}{r}28.98 \\
87 \% \\
88 \% \\
15 \% \\
2 \% \\
\end{array}$ & $\begin{array}{r}27.90 \\
70 \% \\
45 \% \\
10 \% \\
44 \% \\
\end{array}$ & $\begin{array}{r}16.89 \\
89 \% \\
54 \% \\
11 \% \\
16 \% \\
\end{array}$ & $\begin{array}{r}31.15 \\
81 \% \\
81 \% \\
14 \% \\
13 \% \\
\end{array}$ \\
\hline $\begin{array}{l}\text { Fertility Knowledge } \\
\text { Resp knows modern method of contraception } \\
\text { Resp knows ovulation happens at middle of cycle }\end{array}$ & $\begin{array}{l}88 \% \\
19 \% \\
\end{array}$ & $\begin{array}{l}86 \% \\
18 \% \\
\end{array}$ & $\begin{array}{l}93 \% \\
24 \% \\
\end{array}$ & $\begin{array}{l}74 \% \\
11 \% \\
\end{array}$ & $\begin{array}{l}91 \% \\
21 \% \\
\end{array}$ & $\begin{array}{l}88 \% \\
20 \% \\
\end{array}$ & $\begin{array}{l}86 \% \\
18 \% \\
\end{array}$ & $\begin{array}{l}94 \% \\
26 \% \\
\end{array}$ & $\begin{array}{l}74 \% \\
12 \% \\
\end{array}$ & $\begin{array}{l}91 \% \\
22 \% \\
\end{array}$ \\
\hline $\begin{array}{l}\text { Fertility Resources } \\
\text { Has heard FP info from session/radio/tv/newspaper } \\
\text { Has not been pregnant } \\
\text { Any prenatal care* } \\
\text { Checkup after delivery* } \\
\text { Obtained iron tabs or syrup during pregnancy } \\
\text { Tetanus injection during pregnancy* }\end{array}$ & $\begin{array}{l}50 \% \\
32 \% \\
57 \% \\
30 \% \\
54 \% \\
49 \% \\
\end{array}$ & $\begin{array}{l}42 \% \\
26 \% \\
60 \% \\
27 \% \\
57 \% \\
53 \% \\
\end{array}$ & $\begin{array}{l}73 \% \\
49 \% \\
49 \% \\
39 \% \\
46 \% \\
38 \% \\
\end{array}$ & $\begin{array}{l}42 \% \\
73 \% \\
23 \% \\
13 \% \\
21 \% \\
21 \% \\
\end{array}$ & $\begin{array}{l}52 \% \\
23 \% \\
65 \% \\
34 \% \\
61 \% \\
55 \% \\
\end{array}$ & $\begin{array}{l}51 \% \\
32 \% \\
57 \% \\
31 \% \\
54 \% \\
49 \% \\
\end{array}$ & $\begin{array}{l}42 \% \\
26 \% \\
59 \% \\
27 \% \\
56 \% \\
52 \% \\
\end{array}$ & $\begin{array}{l}74 \% \\
46 \% \\
52 \% \\
41 \% \\
48 \% \\
39 \% \\
\end{array}$ & $\begin{array}{l}42 \% \\
73 \% \\
23 \% \\
13 \% \\
22 \% \\
22 \% \\
\end{array}$ & $\begin{array}{l}53 \% \\
23 \% \\
64 \% \\
34 \% \\
61 \% \\
54 \% \\
\end{array}$ \\
\hline $\begin{array}{l}\text { Fertility Agency } \\
\text { Not sexually active } \\
\text { Can ask for condom use } \sim \\
\text { Can refuse sex } \sim \\
\end{array}$ & $\begin{array}{l}16 \% \\
19 \% \\
27 \% \\
\end{array}$ & $\begin{array}{r}8 \% \\
18 \% \\
28 \% \\
\end{array}$ & $\begin{array}{l}36 \% \\
20 \% \\
23 \% \\
\end{array}$ & $\begin{array}{l}50 \% \\
11 \% \\
17 \% \\
\end{array}$ & $\begin{array}{r}8 \% \\
20 \% \\
29 \% \\
\end{array}$ & $\begin{array}{l}15 \% \\
19 \% \\
27 \% \\
\end{array}$ & $\begin{array}{r}8 \% \\
18 \% \\
28 \% \\
\end{array}$ & $\begin{array}{l}33 \% \\
23 \% \\
24 \% \\
\end{array}$ & $\begin{array}{l}49 \% \\
10 \% \\
17 \% \\
\end{array}$ & $\begin{array}{r}8 \% \\
21 \% \\
29 \% \\
\end{array}$ \\
\hline $\begin{array}{l}\text { Food Resources } \\
\text { Agricultural land size (Ha) } \\
\text { Respondent owns land alone } \\
\text { Husband working } \\
\text { Respondent is currently working }\end{array}$ & $\begin{array}{r}27.31 \\
17 \% \\
88 \% \\
23 \%\end{array}$ & $\begin{array}{r}33.49 \\
21 \% \\
94 \% \\
20 \%\end{array}$ & $\begin{array}{r}9.31 \\
6 \% \\
70 \% \\
30 \%\end{array}$ & $\begin{array}{r}24.54 \\
10 \% \\
52 \% \\
13 \%\end{array}$ & $\begin{array}{r}27.92 \\
18 \% \\
96 \% \\
25 \%\end{array}$ & $\begin{array}{r}26.84 \\
17 \% \\
89 \% \\
23 \%\end{array}$ & $\begin{array}{r}33.58 \\
20 \% \\
94 \% \\
20 \%\end{array}$ & $\begin{array}{r}9.15 \\
7 \% \\
74 \% \\
32 \%\end{array}$ & $\begin{array}{r}25.02 \\
10 \% \\
52 \% \\
14 \%\end{array}$ & $\begin{array}{r}27.31 \\
18 \% \\
96 \% \\
25 \%\end{array}$ \\
\hline
\end{tabular}




\begin{tabular}{|c|c|c|c|c|c|c|c|c|c|c|}
\hline \multicolumn{11}{|l|}{ Food Agency } \\
\hline Respondent alone decides on large $\mathrm{HH}$ purchases & $2 \%$ & $2 \%$ & $3 \%$ & $1 \%$ & $3 \%$ & $2 \%$ & $2 \%$ & $4 \%$ & $1 \%$ & $3 \%$ \\
\hline If refused to prepare food: Never justified in beating wife & $58 \%$ & $54 \%$ & $70 \%$ & $58 \%$ & $59 \%$ & $59 \%$ & $54 \%$ & $71 \%$ & $57 \%$ & $59 \%$ \\
\hline \multicolumn{11}{|l|}{ Health Knowledge } \\
\hline Resp heard of AIDS & $85 \%$ & $81 \%$ & $96 \%$ & $81 \%$ & $86 \%$ & $86 \%$ & $82 \%$ & $96 \%$ & $82 \%$ & $87 \%$ \\
\hline Resp heard of or used ORS & $90 \%$ & $90 \%$ & $92 \%$ & $77 \%$ & $93 \%$ & $90 \%$ & $89 \%$ & $92 \%$ & $77 \%$ & $93 \%$ \\
\hline Resp heard of STI & $87 \%$ & $84 \%$ & $96 \%$ & $82 \%$ & $88 \%$ & $88 \%$ & $84 \%$ & $97 \%$ & $82 \%$ & $89 \%$ \\
\hline \multicolumn{11}{|l|}{ Health Resources } \\
\hline HH uses gas, electric, charcoal or cooks outside & $4 \%$ & $0 \%$ & $13 \%$ & $5 \%$ & $3 \%$ & $4 \%$ & $0 \%$ & $14 \%$ & $5 \%$ & $4 \%$ \\
\hline Visited health facility in past 12 months & $46 \%$ & $46 \%$ & $47 \%$ & $28 \%$ & $50 \%$ & $47 \%$ & $46 \%$ & $48 \%$ & $28 \%$ & $50 \%$ \\
\hline $\mathrm{HH}$ has improved toilet & $26 \%$ & $8 \%$ & $78 \%$ & $31 \%$ & $25 \%$ & $27 \%$ & $8 \%$ & $78 \%$ & $31 \%$ & $27 \%$ \\
\hline Resp washes hands with soap and water & $51 \%$ & $42 \%$ & $77 \%$ & $55 \%$ & $50 \%$ & $52 \%$ & $42 \%$ & $77 \%$ & $55 \%$ & $51 \%$ \\
\hline Improved and/or treated water source & $75 \%$ & $67 \%$ & $98 \%$ & $75 \%$ & $75 \%$ & $76 \%$ & $67 \%$ & $98 \%$ & $75 \%$ & $76 \%$ \\
\hline Resp spends less than 1 hour fetching water & $18 \%$ & $4 \%$ & $59 \%$ & $25 \%$ & $17 \%$ & $19 \%$ & $4 \%$ & $59 \%$ & $24 \%$ & $19 \%$ \\
\hline \multicolumn{11}{|l|}{ Health Agency } \\
\hline Resp can get a condom & $8 \%$ & $5 \%$ & $18 \%$ & $7 \%$ & $9 \%$ & $9 \%$ & $5 \%$ & $19 \%$ & $6 \%$ & $10 \%$ \\
\hline $\begin{array}{l}\text { Thinks woman is justified in asking for condom use if } \\
\text { partner has STI }\end{array}$ & $69 \%$ & $68 \%$ & $74 \%$ & $62 \%$ & $71 \%$ & $70 \%$ & $68 \%$ & $75 \%$ & $62 \%$ & $72 \%$ \\
\hline Resp has no problem going to treatment alone & $75 \%$ & $75 \%$ & $76 \%$ & $71 \%$ & $76 \%$ & $76 \%$ & $75 \%$ & $77 \%$ & $71 \%$ & $77 \%$ \\
\hline \multicolumn{11}{|l|}{ Institutions } \\
\hline Resp has a bank account & $6 \%$ & $1 \%$ & $20 \%$ & $9 \%$ & $5 \%$ & $6 \%$ & $1 \%$ & $20 \%$ & $9 \%$ & $5 \%$ \\
\hline Resp has electricity & $23 \%$ & $7 \%$ & $67 \%$ & $30 \%$ & $21 \%$ & $24 \%$ & $7 \%$ & $69 \%$ & $29 \%$ & $23 \%$ \\
\hline Resp ever listens to radio & $61 \%$ & $57 \%$ & $74 \%$ & $60 \%$ & $62 \%$ & $62 \%$ & $57 \%$ & $74 \%$ & $60 \%$ & $62 \%$ \\
\hline Generally: Never justified in beating wife & $41 \%$ & $38 \%$ & $49 \%$ & $40 \%$ & $41 \%$ & $41 \%$ & $38 \%$ & $49 \%$ & $41 \%$ & $41 \%$ \\
\hline
\end{tabular}

Note: These figures are population shares. Women who are not sexually active are included in the denominator. $*$ These figures are population shares. Women

who did not receive postnatal or antenatal care may not have been pregnant. Descriptive statistics for all indicators in Niger model are included in the supplementary materials. Regional descriptive statistics are available upon request. 
Table 3: Shapley-Owen decompositions (as percentage of R-squared)

\begin{tabular}{|c|c|c|c|c|c|c|c|c|c|c|c|c|}
\hline & $\begin{array}{c}\text { Food } \\
\text { Resource }\end{array}$ & $\begin{array}{c}\text { Food } \\
\text { Agency }\end{array}$ & $\begin{array}{c}\text { Health } \\
\text { Knowledge }\end{array}$ & $\begin{array}{c}\text { Health } \\
\text { Resource }\end{array}$ & $\begin{array}{l}\text { Health } \\
\text { Agency }\end{array}$ & $\begin{array}{c}\text { Fertility } \\
\text { Knowledge }\end{array}$ & $\begin{array}{c}\text { Fertility } \\
\text { Resource }\end{array}$ & $\begin{array}{l}\text { Fertility } \\
\text { Agency }\end{array}$ & Institutions & Controls & $\begin{array}{c}\mathrm{R}- \\
\text { squared }\end{array}$ & $\mathrm{n}$ \\
\hline \multicolumn{13}{|l|}{ BMI } \\
\hline Aggregate & $11.43 \%$ & $2.54 \%$ & $6.15 \%$ & $11.48 \%$ & $3.92 \%$ & $3.63 \%$ & $17.76 \%$ & $4.81 \%$ & $11.77 \%$ & $26.51 \%$ & $23.24 \%$ & 4236 \\
\hline$<20$ years old & $8.45 \%$ & $3.45 \%$ & $3.30 \%$ & $22.73 \%$ & $3.69 \%$ & $3.74 \%$ & $16.09 \%$ & $4.27 \%$ & $6.90 \%$ & $27.38 \%$ & $36.93 \%$ & 768 \\
\hline $20+$ years old & $10.19 \%$ & $1.05 \%$ & $7.03 \%$ & $16.01 \%$ & $2.33 \%$ & $3.22 \%$ & $19.85 \%$ & $3.54 \%$ & $11.39 \%$ & $25.37 \%$ & $20.50 \%$ & 3468 \\
\hline Urban & $11.02 \%$ & $5.03 \%$ & $3.67 \%$ & $11.05 \%$ & $5.37 \%$ & $3.16 \%$ & $19.64 \%$ & $7.63 \%$ & $11.45 \%$ & $21.98 \%$ & $39.19 \%$ & 1083 \\
\hline Rural & $9.60 \%$ & $2.73 \%$ & $7.27 \%$ & $14.41 \%$ & $5.65 \%$ & $3.93 \%$ & $19.61 \%$ & $3.32 \%$ & $8.89 \%$ & $24.61 \%$ & $20.82 \%$ & 3153 \\
\hline \multicolumn{13}{|l|}{ Anemia } \\
\hline Aggregate & $5.54 \%$ & $2.54 \%$ & $10.75 \%$ & $19.33 \%$ & $1.60 \%$ & $5.73 \%$ & $15.62 \%$ & $5.04 \%$ & $4.94 \%$ & $28.91 \%$ & $10.55 \%$ & 4326 \\
\hline$<20$ years old & $7.64 \%$ & $2.67 \%$ & $7.27 \%$ & $24.49 \%$ & $3.48 \%$ & $4.76 \%$ & $18.07 \%$ & $3.58 \%$ & $6.04 \%$ & $22.00 \%$ & $27.09 \%$ & 749 \\
\hline $20+$ years old & $5.92 \%$ & $2.49 \%$ & $9.66 \%$ & $17.56 \%$ & $1.59 \%$ & $5.62 \%$ & $16.01 \%$ & $6.27 \%$ & $6.31 \%$ & $28.55 \%$ & $11.96 \%$ & 3577 \\
\hline Urban & $7.63 \%$ & $3.87 \%$ & $11.57 \%$ & $18.33 \%$ & $1.53 \%$ & $3.79 \%$ & $20.36 \%$ & $2.95 \%$ & $3.80 \%$ & $26.17 \%$ & $18.51 \%$ & 1193 \\
\hline Rural & $5.51 \%$ & $3.38 \%$ & $8.18 \%$ & $20.83 \%$ & $1.44 \%$ & $5.95 \%$ & $18.23 \%$ & $5.05 \%$ & $7.30 \%$ & $24.13 \%$ & $13.16 \%$ & 3133 \\
\hline
\end{tabular}

Note: Controls include pregnancy status, number of months pregnant, marital status, age, age-squared, literacy, educational attainment, and partner's educational attainment; household sex ratio, dependency ratio by gender, exposure to shocks, floor material, wall material, roofing material, month of interview and the DHS wealth index. There are no indicators in the food knowledge domain-dimension because there were no relevant questions asked about food knowledge in the 2012 Niger DHS survey. 
Table 4: Shapley-Owen regional decompositions (as percentage of R-squared)

\begin{tabular}{|c|c|c|c|c|c|c|c|c|c|c|c|c|}
\hline & $\begin{array}{c}\text { Food } \\
\text { Resource }\end{array}$ & $\begin{array}{c}\text { Food } \\
\text { Agency }\end{array}$ & $\begin{array}{c}\text { Health } \\
\text { Knowledge }\end{array}$ & $\begin{array}{c}\text { Health } \\
\text { Resource }\end{array}$ & $\begin{array}{l}\text { Health } \\
\text { Agency }\end{array}$ & $\begin{array}{c}\text { Fertility } \\
\text { Knowledge }\end{array}$ & $\begin{array}{l}\text { Fertility } \\
\text { Resource }\end{array}$ & $\begin{array}{l}\text { Fertility } \\
\text { Agency }\end{array}$ & Institutions & Controls & $\begin{array}{c}\text { R- } \\
\text { squared }\end{array}$ & $\mathrm{n}$ \\
\hline \multicolumn{13}{|l|}{$B M I$} \\
\hline Agadez & $13.65 \%$ & $4.80 \%$ & $6.49 \%$ & $12.43 \%$ & $5.12 \%$ & $2.80 \%$ & $18.39 \%$ & $5.87 \%$ & $11.72 \%$ & $18.73 \%$ & $72.58 \%$ & 252 \\
\hline Diffa & $9.28 \%$ & $2.99 \%$ & $6.48 \%$ & $18.83 \%$ & $2.66 \%$ & $4.91 \%$ & $17.20 \%$ & $3.93 \%$ & $10.45 \%$ & $23.26 \%$ & $56.87 \%$ & 370 \\
\hline Dosso & $7.98 \%$ & $3.17 \%$ & $6.16 \%$ & $20.12 \%$ & $5.66 \%$ & $3.14 \%$ & $17.03 \%$ & $5.08 \%$ & $8.36 \%$ & $23.31 \%$ & $43.64 \%$ & 643 \\
\hline Maradi & $5.19 \%$ & $2.32 \%$ & $3.36 \%$ & $20.25 \%$ & $3.02 \%$ & $2.72 \%$ & $16.29 \%$ & $3.39 \%$ & $14.66 \%$ & $28.80 \%$ & $41.51 \%$ & 801 \\
\hline Tahoua & $8.68 \%$ & $1.39 \%$ & $6.32 \%$ & $12.82 \%$ & $3.80 \%$ & $7.26 \%$ & $21.18 \%$ & $5.23 \%$ & $7.51 \%$ & $25.81 \%$ & $44.35 \%$ & 702 \\
\hline Tillaberi & $10.62 \%$ & $3.49 \%$ & $6.29 \%$ & $14.30 \%$ & $5.08 \%$ & $5.18 \%$ & $19.25 \%$ & $6.65 \%$ & $9.73 \%$ & $19.40 \%$ & $51.90 \%$ & 545 \\
\hline Zinder & $9.04 \%$ & $2.27 \%$ & $6.98 \%$ & $21.73 \%$ & $2.64 \%$ & $4.59 \%$ & $14.35 \%$ & $4.81 \%$ & $12.23 \%$ & $21.37 \%$ & $50.84 \%$ & 518 \\
\hline Niamey & $10.48 \%$ & $4.75 \%$ & $3.06 \%$ & $15.80 \%$ & $5.21 \%$ & $2.89 \%$ & $20.54 \%$ & $7.22 \%$ & $8.39 \%$ & $21.68 \%$ & $59.94 \%$ & 405 \\
\hline \multicolumn{13}{|l|}{ Anemia } \\
\hline Agadez & $8.59 \%$ & $1.95 \%$ & $3.98 \%$ & $22.68 \%$ & $3.76 \%$ & $3.58 \%$ & $22.47 \%$ & $6.73 \%$ & $9.40 \%$ & $16.86 \%$ & $66.38 \%$ & 269 \\
\hline Diffa & $9.72 \%$ & $3.59 \%$ & $7.63 \%$ & $15.38 \%$ & $3.22 \%$ & $2.93 \%$ & $25.25 \%$ & $5.71 \%$ & $10.39 \%$ & $16.18 \%$ & $67.16 \%$ & 368 \\
\hline Dosso & $8.19 \%$ & $2.89 \%$ & $5.38 \%$ & $21.84 \%$ & $4.39 \%$ & $3.61 \%$ & $21.12 \%$ & $4.48 \%$ & $6.45 \%$ & $21.65 \%$ & $36.84 \%$ & 665 \\
\hline Tahoua & $10.06 \%$ & $1.60 \%$ & $8.68 \%$ & $21.69 \%$ & $2.33 \%$ & $3.90 \%$ & $21.56 \%$ & $3.97 \%$ & $8.02 \%$ & $18.19 \%$ & $32.13 \%$ & 717 \\
\hline Tillaberi & $9.20 \%$ & $1.21 \%$ & $4.27 \%$ & $17.68 \%$ & $1.46 \%$ & $2.88 \%$ & $25.59 \%$ & $1.46 \%$ & $6.99 \%$ & $29.27 \%$ & $36.70 \%$ & 565 \\
\hline Zinder & $9.76 \%$ & $2.25 \%$ & $7.82 \%$ & $19.62 \%$ & $4.99 \%$ & $2.08 \%$ & $19.85 \%$ & $4.74 \%$ & $7.77 \%$ & $21.13 \%$ & $45.79 \%$ & 494 \\
\hline Niamey & $8.91 \%$ & $4.26 \%$ & $6.35 \%$ & $20.96 \%$ & $5.09 \%$ & $2.49 \%$ & $22.03 \%$ & $6.43 \%$ & $9.22 \%$ & $14.27 \%$ & $41.17 \%$ & 471 \\
\hline
\end{tabular}

Note: Controls include: pregnancy status, number of months pregnant, marital status, age, age-squared, literacy, educational attainment, and partner's educational attainment; household sex ratio, dependency ratio by gender, exposure to shocks, floor material, wall material, roofing material, month of interview and the DHS wealth index. There are no indicators in the food knowledge domain-dimension because there were no relevant questions asked about the domain-dimension in the 2012 Niger DHS survey. 


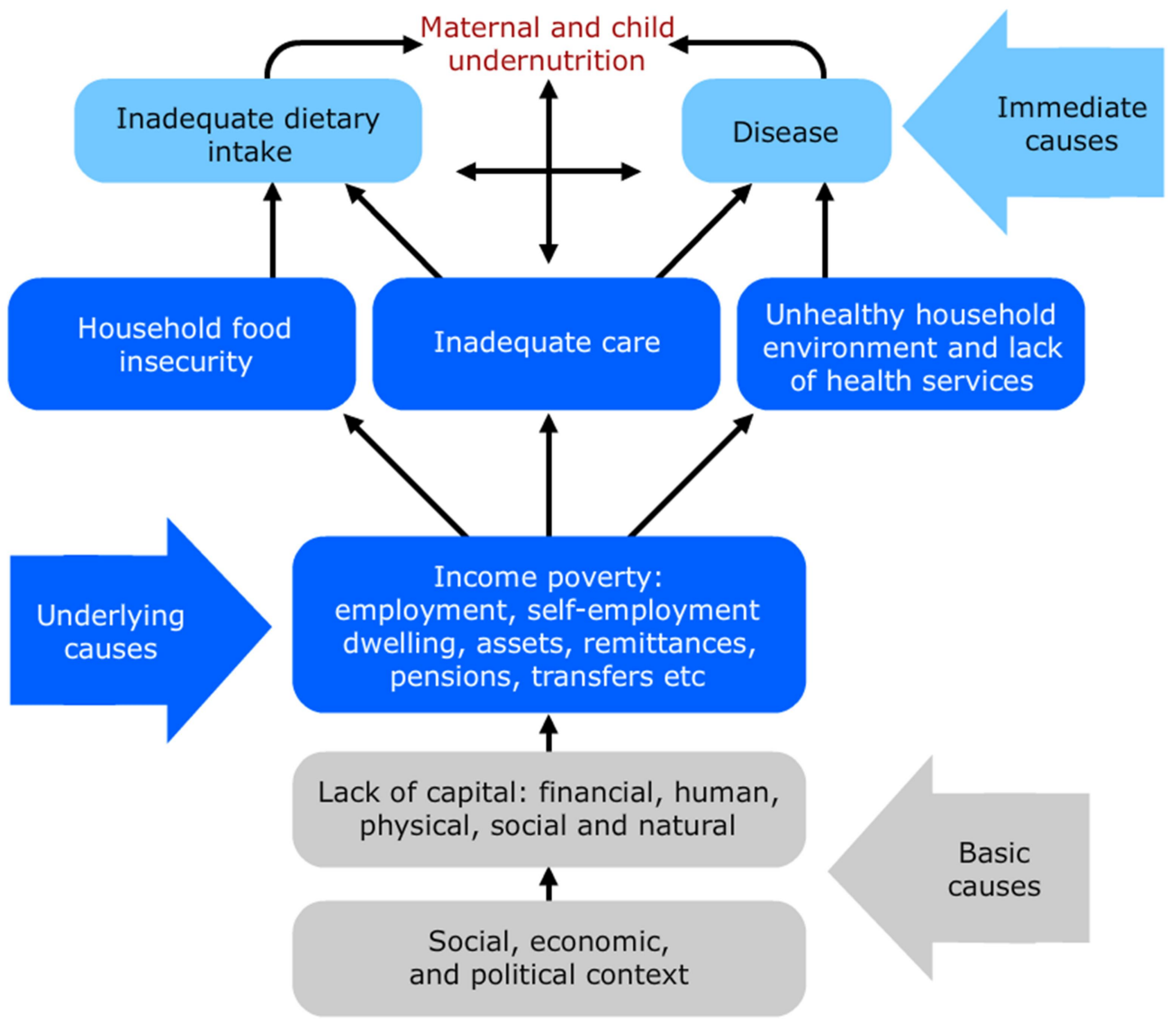

Figure 1. UNICEF's Conceptual Framework (1990, 2018) 


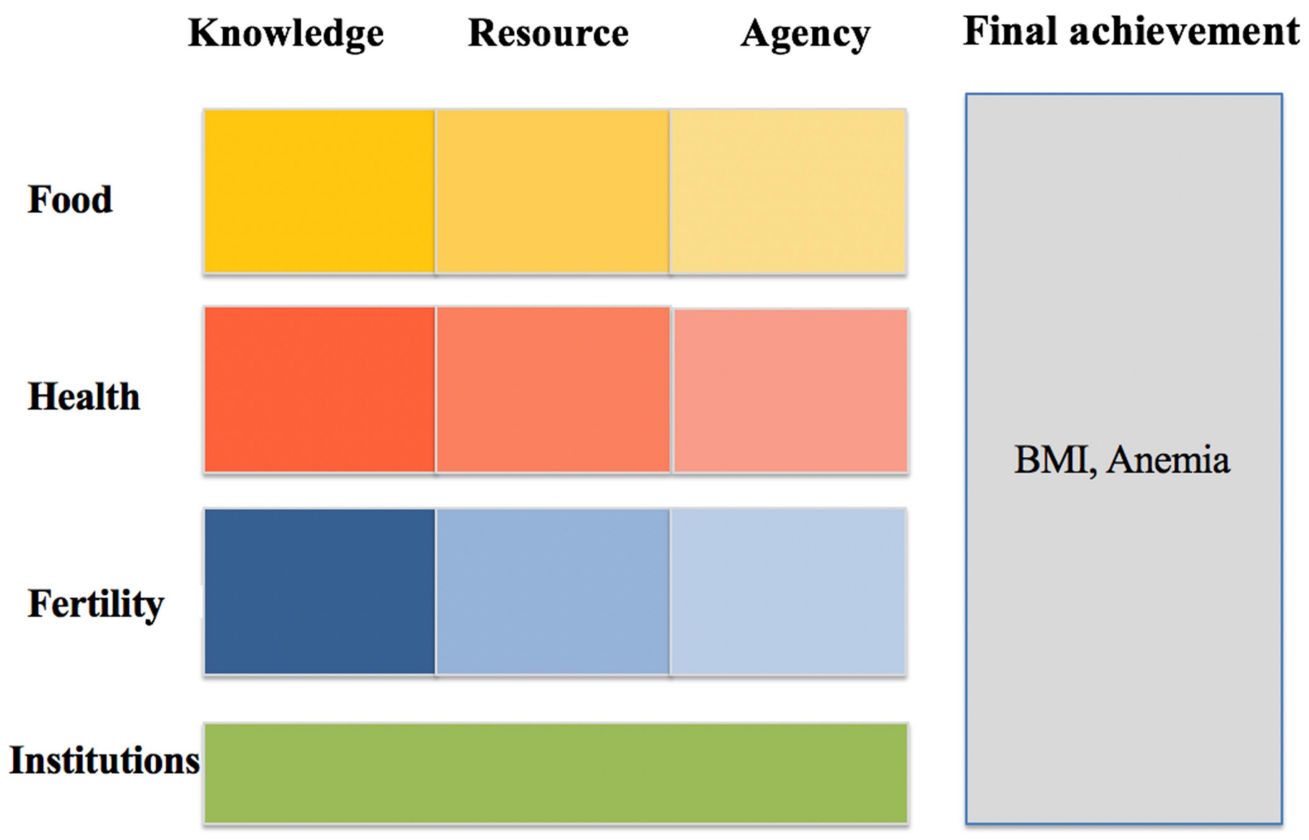

Figure 2: The WEN Grid: Linking nutritional domains and dimensions of empowerment 


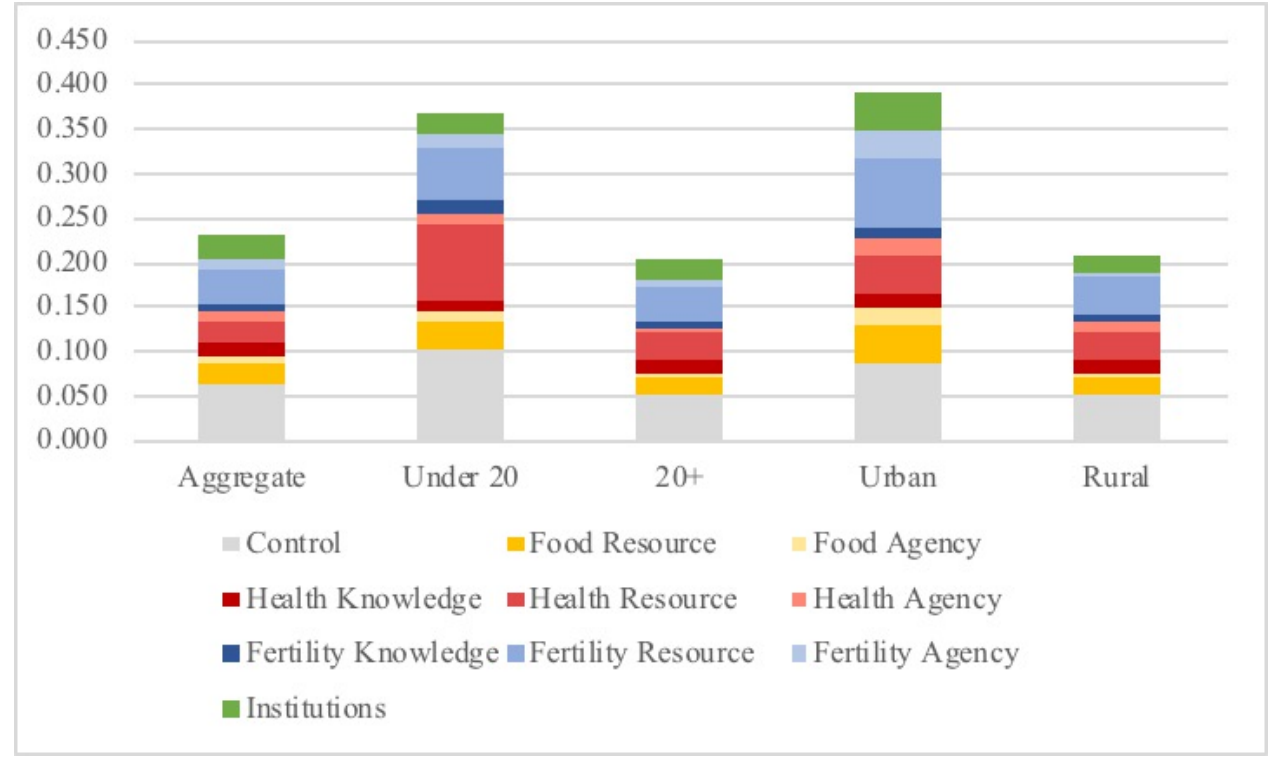

Figure 3: Shapley-Owen Decomposition for BMI 


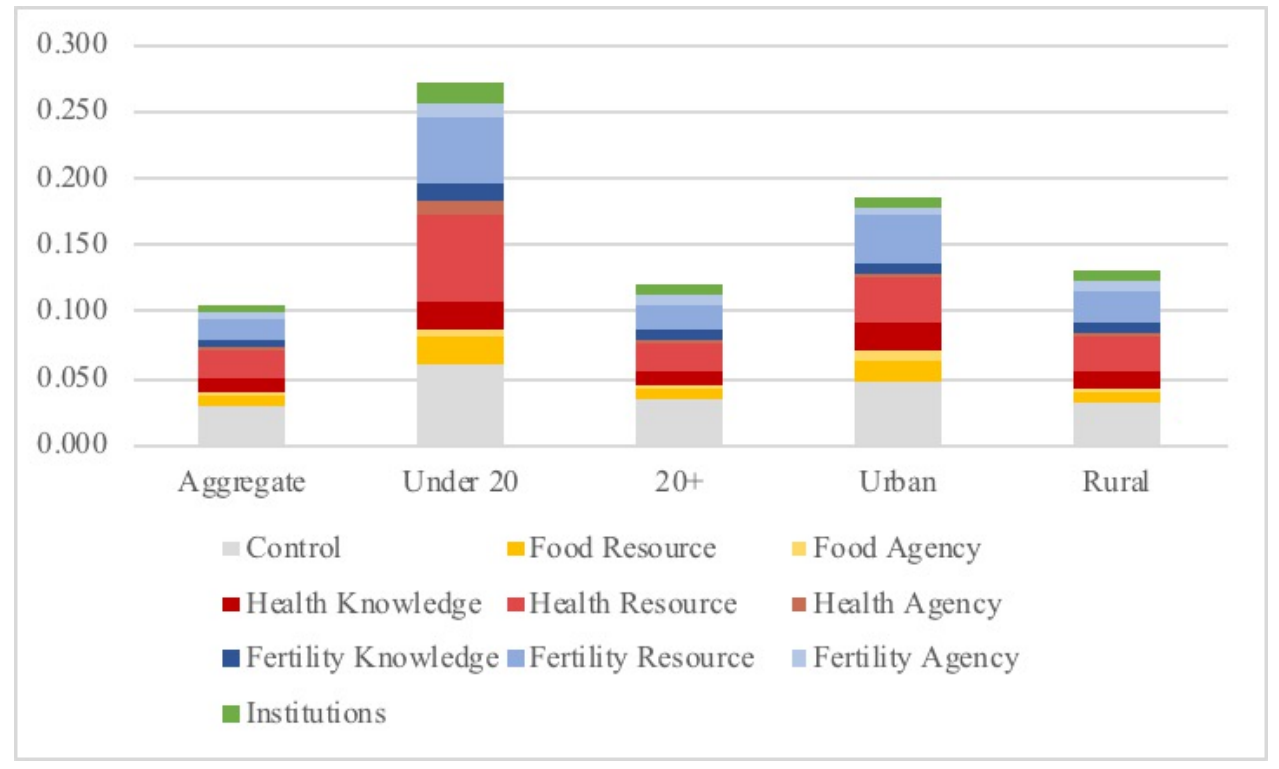

Figure 4: Shapley-Owen Decomposition for Anemia 


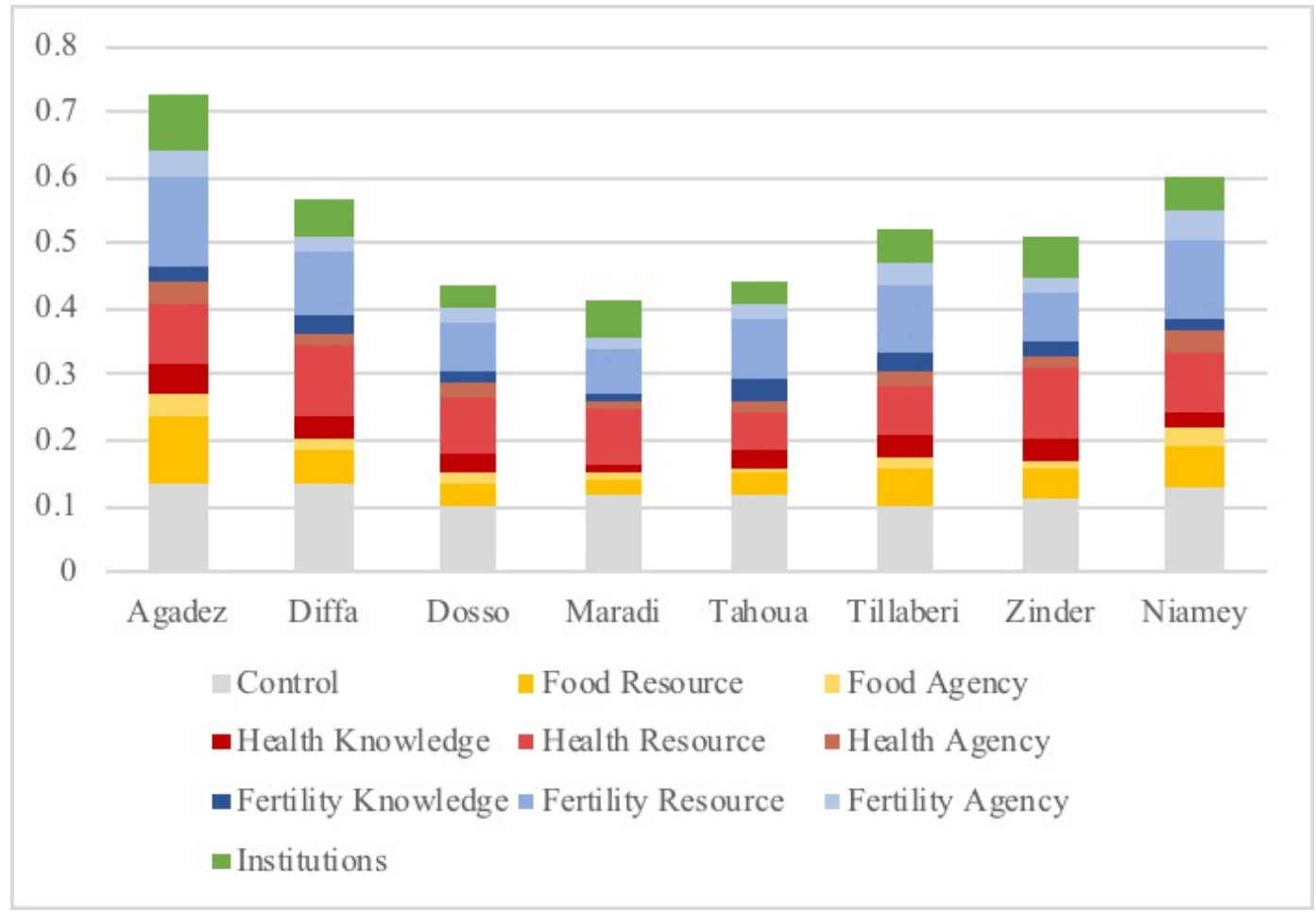

Figure 5: Shapley-Owen Regional Decomposition for BMI 


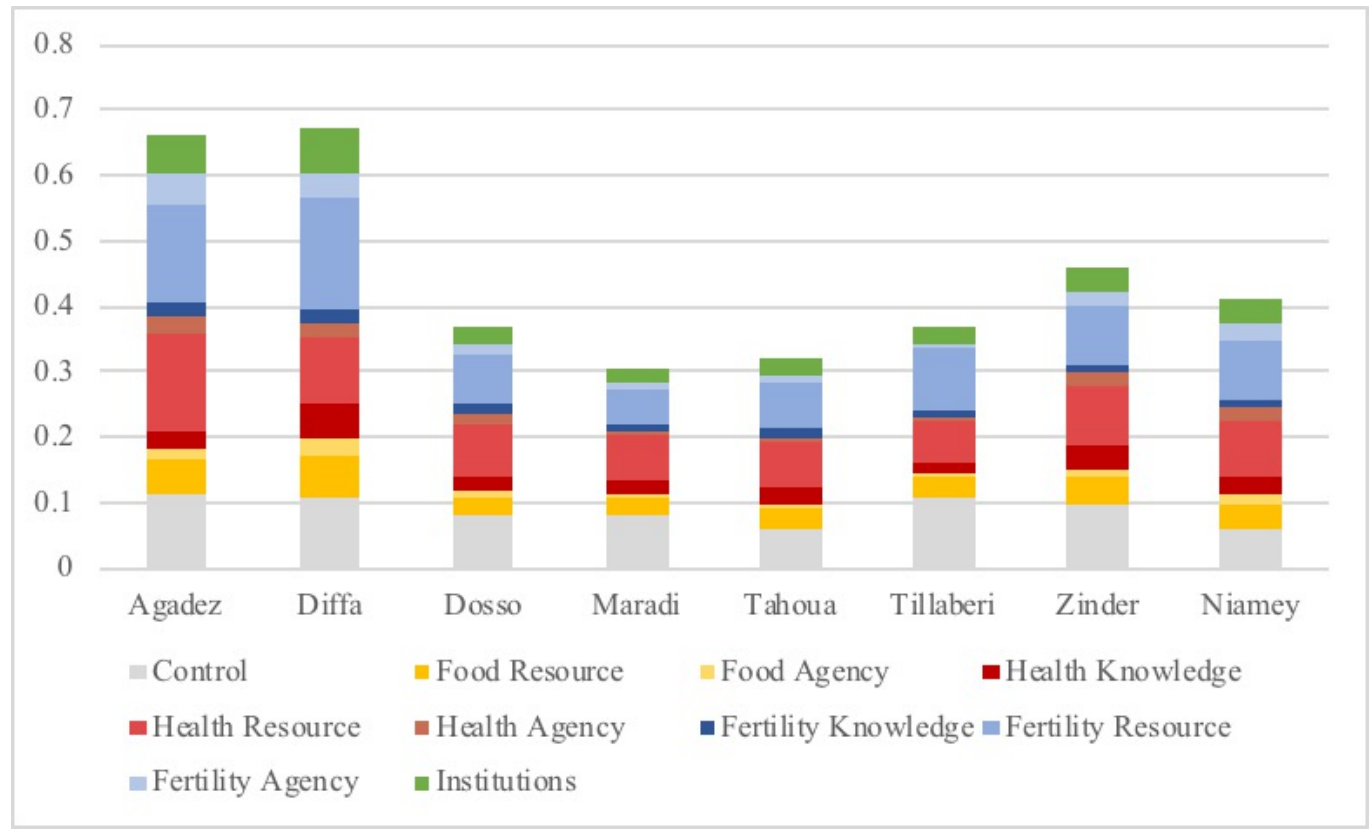

Figure 6: Shapley-Owen Regional Decomposition for Anemia Status 


\section{Supplementary Materials:}

\section{Appendix 1: Descriptive Statistics}

Table A1.1: Complete descriptive statistics for aggregate Niger results

\begin{tabular}{|c|c|c|c|c|c|c|}
\hline & \multicolumn{3}{|c|}{ BMI $(n=4236)$} & \multicolumn{3}{|c|}{ Anemia $(n=4326)$} \\
\hline & Mean & Std Dev & Median & Mean & Std Dev & Median \\
\hline \multicolumn{7}{|l|}{ Outcomes } \\
\hline Any anemia (mild, moderate, severe) & 0.55 & 0.50 & 1 & 0.55 & 0.50 & 1 \\
\hline Respondent BMI & 21.71 & 3.11 & 21.41 & 22.30 & 4.10 & 21.63 \\
\hline \multicolumn{7}{|l|}{ Controls } \\
\hline Woman's age in years & 28.42 & 8.98 & 27 & 28.68 & 8.97 & 28 \\
\hline Woman's age in years, squared & 888.23 & 551.36 & 729 & 903.18 & 552.62 & 784 \\
\hline Resp has one or more chronic disease & $17 \%$ & 0.38 & 0 & $18 \%$ & 0.38 & 0 \\
\hline Resp free of chronic disease & $83 \%$ & 0.38 & 1 & $82 \%$ & 0.38 & 1 \\
\hline Share of HH age $15-64$ & $45 \%$ & 0.19 & 0.40 & $45 \%$ & 0.19 & 0.40 \\
\hline Share of women in HH age 15-64 & $27 \%$ & 0.17 & 0.27 & $27 \%$ & 0.17 & 0.27 \\
\hline Share of men in $\mathrm{HH}$ age $15-64$ & $28 \%$ & 0.17 & 0.29 & $28 \%$ & 0.17 & 0.29 \\
\hline No education & $77 \%$ & 0.42 & 1 & $76 \%$ & 0.43 & 1 \\
\hline Primary education & $12 \%$ & 0.33 & 0 & $13 \%$ & 0.33 & 0 \\
\hline Secondary education & $11 \%$ & 0.31 & 0 & $10 \%$ & 0.31 & 0 \\
\hline Post-secondary education & $1 \%$ & 0.07 & 0 & $1 \%$ & 0.08 & 0 \\
\hline N/A (no husband) & $12 \%$ & 0.32 & 0 & $11 \%$ & 0.31 & 0 \\
\hline Husband no education & $70 \%$ & 0.46 & 1 & $69 \%$ & 0.46 & 1 \\
\hline Husband primary education & $10 \%$ & 0.30 & 0 & $11 \%$ & 0.31 & 0 \\
\hline Husband secondary education & $6 \%$ & 0.23 & 0 & $6 \%$ & 0.24 & 0 \\
\hline Husband post-secondary education & $1 \%$ & 0.12 & 0 & $2 \%$ & 0.13 & 0 \\
\hline Doesn't know husband education level & $1 \%$ & 0.11 & 0 & $1 \%$ & 0.11 & 0 \\
\hline Floor: Dirt/sand/palm/bamboo/other & $76 \%$ & 0.43 & 1 & $74 \%$ & 0.44 & 1 \\
\hline Floor: Wood/vinyl/asphalt/cement/tile/carpet & $24 \%$ & 0.43 & 0 & $26 \%$ & 0.44 & 0 \\
\hline Cannot read at all & $83 \%$ & 0.38 & 1 & $82 \%$ & 0.38 & 1 \\
\hline Able to read only parts of a sentence & $3 \%$ & 0.18 & 0 & $4 \%$ & 0.19 & 0 \\
\hline Able to read a whole sentence & $13 \%$ & 0.34 & 0 & $14 \%$ & 0.35 & 0 \\
\hline Never in union & $12 \%$ & 0.32 & 0 & $11 \%$ & 0.31 & 0 \\
\hline Married/cohabiting & $84 \%$ & 0.36 & 1 & $85 \%$ & 0.36 & 1 \\
\hline Widowed & $1 \%$ & 0.11 & 0 & $1 \%$ & 0.11 & 0 \\
\hline Divorced/separated & $3 \%$ & 0.16 & 0 & $3 \%$ & 0.16 & 0 \\
\hline Woman is not obese & $100 \%$ & 0.00 & 1 & $95 \%$ & 0.21 & 1 \\
\hline Woman is obese & $0 \%$ & 0.00 & 0 & $5 \%$ & 0.21 & 0 \\
\hline Not pregnant or unsure & $86 \%$ & 0.34 & 1 & $86 \%$ & 0.34 & 1 \\
\hline Pregnant & $14 \%$ & 0.34 & 0 & $14 \%$ & 0.34 & 0 \\
\hline $\begin{array}{l}\text { Duration of current pregnancy (months); } 0=\text { not } \\
\text { pregnant }\end{array}$ & $73 \%$ & 1.99 & 0 & $73 \%$ & 1.99 & 0 \\
\hline $\begin{array}{l}\text { Roof: none/thatch/palm/sod/mat/ } \\
\text { bamboo/wood/cardboard/other }\end{array}$ & $85 \%$ & 0.35 & 1 & $84 \%$ & 0.36 & 1 \\
\hline Roof: metal/zinc/cement/shingles & $15 \%$ & 0.35 & 0 & $16 \%$ & 0.36 & 0 \\
\hline Female-to-male ratio in household & $54 \%$ & 0.17 & 0.5 & $54 \%$ & 0.17 & 0.5 \\
\hline No shock experienced & $22 \%$ & 0.41 & 0 & $23 \%$ & 0.42 & 0 \\
\hline Environmental shock & $46 \%$ & 0.50 & 0 & $45 \%$ & 0.50 & 0 \\
\hline
\end{tabular}




\begin{tabular}{|c|c|c|c|c|c|c|}
\hline Health shock & $18 \%$ & 0.39 & 0 & $19 \%$ & 0.39 & 0 \\
\hline Economic shock & $8 \%$ & 0.28 & 0 & $9 \%$ & 0.28 & 0 \\
\hline Conflict shock & $4 \%$ & 0.19 & 0 & $4 \%$ & 0.18 & 0 \\
\hline Other shock & $1 \%$ & 0.11 & 0 & $1 \%$ & 0.11 & 0 \\
\hline $\begin{array}{l}\text { Walls: none/bamboo/cane /palm/dirt/ straw/sheet } \\
\text { metal/other }\end{array}$ & $88 \%$ & 0.32 & 1 & $87 \%$ & 0.34 & 1 \\
\hline Walls: cement/stone/wood/brick/block & $12 \%$ & 0.32 & 0 & $13 \%$ & 0.34 & 0 \\
\hline National wealth index: Poorest & $16 \%$ & 0.37 & 0 & $16 \%$ & 0.36 & 0 \\
\hline National wealth index: Poorer & $17 \%$ & 0.38 & 0 & $17 \%$ & 0.37 & 0 \\
\hline National wealth index: Middle & $19 \%$ & 0.39 & 0 & $18 \%$ & 0.39 & 0 \\
\hline National wealth index: Richer & $21 \%$ & 0.40 & 0 & $20 \%$ & 0.40 & 0 \\
\hline National wealth index: Richest & $27 \%$ & 0.45 & 0 & $29 \%$ & 0.46 & 0 \\
\hline \multicolumn{7}{|l|}{ Fertility Agency } \\
\hline N/A category (missing value due to skip pattern) & $57 \%$ & 0.50 & 1 & $55 \%$ & 0.50 & 1 \\
\hline Resp believe fem circumcision ok or "it depends" & $5 \%$ & 0.22 & 0 & $5 \%$ & 0.22 & 0 \\
\hline Resp believes fem circumcision should stop & $38 \%$ & 0.49 & 0 & $40 \%$ & 0.49 & 0 \\
\hline N/A category (not sexually active) & $16 \%$ & 0.36 & 0 & $15 \%$ & 0.36 & 0 \\
\hline $\begin{array}{l}\text { Resp can't ask for condom use, is unsure or "it } \\
\text { depends" }\end{array}$ & $66 \%$ & 0.47 & 1 & $66 \%$ & 0.48 & 1 \\
\hline Resp can ask for condom use & $19 \%$ & 0.39 & 0 & $19 \%$ & 0.39 & 0 \\
\hline $\begin{array}{l}\text { Uses non-woman controlled FP method or no } \\
\text { method }\end{array}$ & $42 \%$ & 0.49 & 0 & $42 \%$ & 0.49 & 0 \\
\hline $\begin{array}{l}\text { Currently uses woman-controlled FP method or } \\
\text { intentionally not using }\end{array}$ & $58 \%$ & 0.49 & 1 & $58 \%$ & 0.49 & 1 \\
\hline N/A category (e.g. not in union) & $88 \%$ & 0.33 & 1 & $87 \%$ & 0.34 & 1 \\
\hline FP decision made by partner/ joint/other & $7 \%$ & 0.25 & 0 & $7 \%$ & 0.26 & 0 \\
\hline Mainly respondent makes FP decisions & $5 \%$ & 0.22 & 0 & $6 \%$ & 0.23 & 0 \\
\hline N/A category & $70 \%$ & 0.46 & 1 & $71 \%$ & 0.45 & 1 \\
\hline External or norm-related opposition to FP & $7 \%$ & 0.25 & 0 & $6 \%$ & 0.25 & 0 \\
\hline No external or norm related opposition to FP & $23 \%$ & 0.42 & 0 & $23 \%$ & 0.42 & 0 \\
\hline N/A category (not sexually active) & $16 \%$ & 0.36 & 0 & $15 \%$ & 0.36 & 0 \\
\hline Resp can't refuse sex, is unsure, or "it depends" & $58 \%$ & 0.49 & 1 & $58 \%$ & 0.49 & 1 \\
\hline Resp can refuse sex & $27 \%$ & 0.44 & 0 & $27 \%$ & 0.44 & 0 \\
\hline \multicolumn{7}{|l|}{ Food Agency } \\
\hline N/A category (e.g. not in union) & $17 \%$ & 0.37 & 0 & $16 \%$ & 0.37 & 0 \\
\hline $\begin{array}{l}\text { Other(s) involved in deciding how to spend } \\
\text { husband earnings }\end{array}$ & $82 \%$ & 0.39 & 1 & $82 \%$ & 0.38 & 1 \\
\hline $\begin{array}{l}\text { Resp alone decides how to spend husband's } \\
\text { earnings }\end{array}$ & $2 \%$ & 0.12 & 0 & $2 \%$ & 0.13 & 0 \\
\hline N/A category (e.g. not in union) & $16 \%$ & 0.36 & 0 & $15 \%$ & 0.36 & 0 \\
\hline $\begin{array}{l}\text { Other(s) involved in deciding on large HH } \\
\text { purchases or doesn't know }\end{array}$ & $82 \%$ & 0.38 & 1 & $82 \%$ & 0.38 & 1 \\
\hline Resp alone decides on large HH purchases & $2 \%$ & 0.15 & 0 & $2 \%$ & 0.16 & 0 \\
\hline N/A category (e.g. not in union) & $79 \%$ & 0.41 & 1 & $78 \%$ & 0.41 & 1 \\
\hline $\begin{array}{l}\text { Other(s) involved in deciding how to spend } \\
\text { earnings or doesn't know }\end{array}$ & $3 \%$ & 0.18 & 0 & $3 \%$ & 0.18 & 0 \\
\hline Resp alone decides how to spend earnings & $18 \%$ & 0.38 & 0 & $18 \%$ & 0.39 & 0 \\
\hline $\begin{array}{l}\text { If refuses to prepare food: Beating sometimes } \\
\text { justified or doesn't know }\end{array}$ & $42 \%$ & 0.49 & 0 & $41 \%$ & 0.49 & 0 \\
\hline $\begin{array}{l}\text { If refused to prepare food: Never justified in } \\
\text { beating wife }\end{array}$ & $58 \%$ & 0.49 & 1 & $59 \%$ & 0.49 & 1 \\
\hline
\end{tabular}




\begin{tabular}{|c|c|c|c|c|c|c|}
\hline Resp doesn't have fridge & $94 \%$ & 0.24 & 1 & $93 \%$ & 0.25 & 1 \\
\hline Resp has fridge & $6 \%$ & 0.24 & 0 & $7 \%$ & 0.25 & 0 \\
\hline Number of HH members (continuous) & 7.59 & 4.14 & 7 & 7.61 & 4.14 & 7 \\
\hline Not in union & $12 \%$ & 0.32 & 0 & $11 \%$ & 0.31 & 0 \\
\hline Husband doesn't work & $0 \%$ & 0.05 & 0 & $0 \%$ & 0.05 & 0 \\
\hline Husband working & $88 \%$ & 0.32 & 1 & $89 \%$ & 0.32 & 1 \\
\hline Agricultural land size (Ha) & $2731 \%$ & 40.38 & 20 & 26.84 & 40.73 & 20 \\
\hline Resp doesn't have oven & $97 \%$ & 0.16 & 1 & $97 \%$ & 0.18 & 1 \\
\hline Resp has oven & $3 \%$ & 0.16 & 0 & $3 \%$ & 0.18 & 0 \\
\hline Resp doesn't own ag land & $24 \%$ & 0.43 & 0 & $25 \%$ & 0.43 & 0 \\
\hline Resp owns ag land & $76 \%$ & 0.43 & 1 & $75 \%$ & 0.43 & 1 \\
\hline $\begin{array}{l}\text { Resp doesn't own house, owns jointly or doesn't } \\
\text { know }\end{array}$ & $87 \%$ & 0.33 & 1 & $87 \%$ & 0.33 & 1 \\
\hline Resp owns home alone & $13 \%$ & 0.33 & 0 & $13 \%$ & 0.33 & 0 \\
\hline $\begin{array}{l}\text { Resp doesn't own land, owns jointly or doesn't } \\
\text { know }\end{array}$ & $83 \%$ & 0.38 & 1 & $83 \%$ & 0.37 & 1 \\
\hline Resp owns land alone & $17 \%$ & 0.38 & 0 & $17 \%$ & 0.37 & 0 \\
\hline Resp doesn't own livestock & $25 \%$ & 0.44 & 0 & $26 \%$ & 0.44 & 0 \\
\hline Resp owns livestock & $75 \%$ & 0.44 & 1 & $74 \%$ & 0.44 & 1 \\
\hline N/A category (not working) & $73 \%$ & 0.44 & 1 & $72 \%$ & 0.45 & 1 \\
\hline Resp not paid & $2 \%$ & 0.13 & 0 & $2 \%$ & 0.13 & 0 \\
\hline Resp paid cash or inkind & $25 \%$ & 0.43 & 0 & $26 \%$ & 0.44 & 0 \\
\hline Has no water pump for irrigation & $98 \%$ & 0.14 & 1 & $98 \%$ & 0.15 & 1 \\
\hline Has water pump for irrigation & $2 \%$ & 0.14 & 0 & $2 \%$ & 0.15 & 0 \\
\hline N/A category (e.g. respondent not employed) & $73 \%$ & 0.44 & 1 & $72 \%$ & 0.45 & 1 \\
\hline Resp is not self-employed & $4 \%$ & 0.18 & 0 & $4 \%$ & 0.19 & 0 \\
\hline Resp is self employed & $23 \%$ & 0.42 & 0 & $24 \%$ & 0.43 & 0 \\
\hline Resp not working or doesn't know & $77 \%$ & 0.42 & 1 & $76 \%$ & 0.43 & 1 \\
\hline Resp is currently working & $23 \%$ & 0.42 & 0 & $23 \%$ & 0.42 & 0 \\
\hline Resp didn't work in past year & $73 \%$ & 0.44 & 1 & $72 \%$ & 0.45 & 1 \\
\hline Resp worked in past year & $27 \%$ & 0.44 & 0 & $28 \%$ & 0.45 & 0 \\
\hline N/A category (not working) & $73 \%$ & 0.44 & 1 & $72 \%$ & 0.45 & 1 \\
\hline Resp works seasonally/occasionally/doesn't know & $16 \%$ & 0.37 & 0 & $16 \%$ & 0.37 & 0 \\
\hline Resp works year round & $11 \%$ & 0.31 & 0 & $12 \%$ & 0.32 & 0 \\
\hline \multicolumn{7}{|l|}{ Fertility Knowledge } \\
\hline Resp knows no modern methods of contraception & $12 \%$ & 0.33 & 0 & $12 \%$ & 0.32 & 0 \\
\hline Resp knows modern method of contraception & $88 \%$ & 0.33 & 1 & $88 \%$ & 0.32 & 1 \\
\hline N/A category (knows about and uses FP) & $70 \%$ & 0.46 & 1 & $71 \%$ & 0.45 & 1 \\
\hline Resp knows of no source/method of FP & $2 \%$ & 0.13 & 0 & $1 \%$ & 0.12 & 0 \\
\hline Resp does not use FP but knows about it & $28 \%$ & 0.45 & 0 & $28 \%$ & 0.45 & 0 \\
\hline N/A category (not in foula program area) & $88 \%$ & 0.33 & 1 & $87 \%$ & 0.34 & 1 \\
\hline Not heard of foula & $4 \%$ & 0.20 & 0 & $4 \%$ & 0.20 & 0 \\
\hline Heard of foula & $8 \%$ & 0.27 & 0 & $9 \%$ & 0.28 & 0 \\
\hline $\begin{array}{l}\text { Resp doesn't know when ovulation happens in } \\
\text { cycle }\end{array}$ & $81 \%$ & 0.40 & 1 & $80 \%$ & 0.40 & 1 \\
\hline Resp knows ovulation happens at middle of cycle & $19 \%$ & 0.40 & 0 & $20 \%$ & 0.40 & 0 \\
\hline N/A category (not in Sumatra program area) & $89 \%$ & 0.32 & 1 & $88 \%$ & 0.33 & 1 \\
\hline Not heard of sumatra & $8 \%$ & 0.27 & 0 & $8 \%$ & 0.27 & 0 \\
\hline Heard of sumatra & $4 \%$ & 0.19 & 0 & $4 \%$ & 0.19 & 0 \\
\hline
\end{tabular}


N/A category (has not had an ANC visit)

Received no HIV info at ANC visit

Received any HIV info at ANC visit

N/A category (has not been pregnant)

No prenatal care

Any prenatal care

N/A category (has not given birth)

Child not immediately put to breast after birth

Child immediately put to breast after birth

N/A category (has not been pregnant or has not had prenatal care)

No blood sample taken during pregnancy

Blood sample taken during pregnancy

N/A category (has not been pregnant or has not

had prenatal care)

No BP taken during pregnancy

$\mathrm{BP}$ taken during pregnancy

N/A category (has not been pregnant)

Resp went to traditional or other person for

checkup after delivery

Resp went to dr/nurse/midwife for checkup after delivery

N/A category (has not been pregnant or has not had prenatal care or checkup)

Checkup $>24$ hours after delivery or doesn't know

Checkup $<24$ hours after delivery

N/A category (has not been pregnant)

Resp didn't go to checkup after delivery

Resp went to checkup after delivery

N/A category (has not been pregnant or has not had prenatal care)

Not told about pregnancy complications

Told about pregnancy complications

N/A category (not sexually active)

Did not use a condom with most recent partner

Used a condom with most recent partner

Never used any method to delay pregnancy

Has used a method to delay pregnancy

N/A category (has not been pregnant)

Delivered at home or other

Delivered in health care facility

N/A category (has not been pregnant)

No prenatal visit with doctor

Had prenatal visit with doctor

Took fansidar $<3 \mathrm{x}$ during pregnancy

Took fansidar $>=3 \mathrm{x}$ during pregnancy

N/A category (no pregnancy or pregnant and no fansidar)

N/A category (has not been to a health clinic in the past 12 months)

Did not hear of FP at health clinic

\begin{tabular}{|c|c|c|c|c|}
\hline $62 \%$ & 0.48 & 1 & $62 \%$ & 0.48 \\
\hline $17 \%$ & 0.37 & 0 & $17 \%$ & 0.37 \\
\hline $21 \%$ & 0.40 & 0 & $21 \%$ & 0.41 \\
\hline $32 \%$ & 0.47 & 0 & $32 \%$ & 0.47 \\
\hline $11 \%$ & 0.32 & 0 & $11 \%$ & 0.31 \\
\hline $57 \%$ & 0.50 & 1 & $57 \%$ & 0.49 \\
\hline $33 \%$ & 0.47 & 0 & $33 \%$ & 0.47 \\
\hline $32 \%$ & 0.47 & 0 & $32 \%$ & 0.47 \\
\hline $35 \%$ & 0.48 & 0 & $35 \%$ & 0.48 \\
\hline $43 \%$ & 0.50 & 0 & $43 \%$ & 0.49 \\
\hline $30 \%$ & 0.46 & 0 & $29 \%$ & 0.45 \\
\hline $27 \%$ & 0.44 & 0 & $28 \%$ & 0.45 \\
\hline $43 \%$ & 0.50 & 0 & $43 \%$ & 0.49 \\
\hline $16 \%$ & 0.37 & 0 & $16 \%$ & 0.37 \\
\hline $41 \%$ & 0.49 & 0 & $41 \%$ & 0.49 \\
\hline $32 \%$ & 0.47 & 0 & $32 \%$ & 0.47 \\
\hline $43 \%$ & 0.50 & 0 & $43 \%$ & 0.49 \\
\hline $25 \%$ & 0.43 & 0 & $26 \%$ & 0.44 \\
\hline $61 \%$ & 0.49 & 1 & $60 \%$ & 0.49 \\
\hline $31 \%$ & 0.46 & 0 & $31 \%$ & 0.46 \\
\hline $8 \%$ & 0.27 & 0 & $9 \%$ & 0.28 \\
\hline $32 \%$ & 0.47 & 0 & $32 \%$ & 0.47 \\
\hline $38 \%$ & 0.49 & 0 & $38 \%$ & 0.48 \\
\hline $30 \%$ & 0.46 & 0 & $31 \%$ & 0.46 \\
\hline $43 \%$ & 0.50 & 0 & $43 \%$ & 0.49 \\
\hline $24 \%$ & 0.43 & 0 & $24 \%$ & 0.43 \\
\hline $33 \%$ & 0.47 & 0 & $33 \%$ & 0.47 \\
\hline $11 \%$ & 0.31 & 0 & $11 \%$ & 0.31 \\
\hline $89 \%$ & 0.32 & 1 & $89 \%$ & 0.31 \\
\hline $0 \%$ & 0.04 & 0 & $0 \%$ & 0.05 \\
\hline $75 \%$ & 0.44 & 1 & $73 \%$ & 0.44 \\
\hline $25 \%$ & 0.44 & 0 & $27 \%$ & 0.44 \\
\hline $32 \%$ & 0.47 & 0 & $32 \%$ & 0.47 \\
\hline $43 \%$ & 0.50 & 0 & $42 \%$ & 0.49 \\
\hline $25 \%$ & 0.43 & 0 & $26 \%$ & 0.44 \\
\hline $32 \%$ & 0.47 & 0 & $32 \%$ & 0.47 \\
\hline $68 \%$ & 0.47 & 1 & $67 \%$ & 0.47 \\
\hline $1 \%$ & 0.08 & 0 & $1 \%$ & 0.09 \\
\hline $36 \%$ & 0.48 & 0 & $36 \%$ & 0.48 \\
\hline $6 \%$ & 0.24 & 0 & $6 \%$ & 0.24 \\
\hline $58 \%$ & 0.49 & 1 & $57 \%$ & 0.49 \\
\hline $54 \%$ & 0.50 & 1 & $53 \%$ & 0.50 \\
\hline $35 \%$ & 0.48 & 0 & $35 \%$ & 0.48 \\
\hline
\end{tabular}


Heard of FP at health clinic

Has not heard FP info from any source

Has heard FP info from

session/radio/tv/newspaper

N/A category (not sexually active)

Knows no source of FP and doesn't use

Knows a source of FP even though doesn't use

No visit from FP worker in past 12 months

Visited by FP worker in past 12 months

N/A category (has not been pregnant or has not had prenatal care)

No iron tabs/syrup during pregnancy or doesn't know

Obtained iron tabs/syrup during pregnancy

N/A category (has not been pregnant or has not had prenatal care)

Iron taken 0 months during pregnancy

Iron taken 1 month during pregnancy

Iron taken 2 months during pregnancy

Iron taken 3 months during pregnancy

Iron taken 4 months during pregnancy

Iron taken 5 months during pregnancy

Iron taken 6 months during pregnancy

N/A category (has not been pregnant or has not had prenatal care)

No prenatal visit with nurse/midwife

Prenatal visit with nurse/midwife

N/A category (has not been pregnant or has not had prenatal care)

No treatment for intestinal parasites during pregnancy

Received treatment for intestinal parasites during pregnancy

N/A category (has not been pregnant or has not had prenatal care)

No tetanus injections during pregnancy or doesn't know

Any tetanus injections during pregnancy

N/A category (has not been pregnant, has not had prenatal care, or did not have symptoms)

No treatment for fever/cough during pregnancy

Received treatment for fever/cough during pregnancy

N/A category (has not been pregnant or has not had prenatal care)

No malaria treatment received during pregnancy

Malaria treatment received during pregnancy

N/A category (has not been pregnant or has not had prenatal care)

No urine taken during pregnancy

Urine taken during pregnancy

N/A category (has not been pregnant or has not had prenatal care)

\begin{tabular}{|c|c|c|c|c|}
\hline $11 \%$ & 0.31 & 0 & $11 \%$ & 0.31 \\
\hline $50 \%$ & 0.50 & 0 & $49 \%$ & 0.50 \\
\hline $50 \%$ & 0.50 & 1 & $51 \%$ & 0.50 \\
\hline $12 \%$ & 0.33 & 0 & $13 \%$ & 0.34 \\
\hline $57 \%$ & 0.49 & 1 & $57 \%$ & 0.49 \\
\hline $30 \%$ & 0.46 & 0 & $29 \%$ & 0.46 \\
\hline $95 \%$ & 0.23 & 1 & $95 \%$ & 0.23 \\
\hline $5 \%$ & 0.23 & 0 & $5 \%$ & 0.23 \\
\hline $32 \%$ & 0.47 & 0 & $32 \%$ & 0.47 \\
\hline $14 \%$ & 0.35 & 0 & $14 \%$ & 0.35 \\
\hline $54 \%$ & 0.50 & 1 & $54 \%$ & 0.50 \\
\hline $46 \%$ & 0.50 & 0 & $46 \%$ & 0.50 \\
\hline $1 \%$ & 0.12 & 0 & $2 \%$ & 0.13 \\
\hline $18 \%$ & 0.39 & 0 & $18 \%$ & 0.39 \\
\hline $15 \%$ & 0.36 & 0 & $15 \%$ & 0.36 \\
\hline $13 \%$ & 0.33 & 0 & $13 \%$ & 0.33 \\
\hline $5 \%$ & 0.21 & 0 & $4 \%$ & 0.21 \\
\hline $2 \%$ & 0.12 & 0 & $2 \%$ & 0.12 \\
\hline $1 \%$ & 0.08 & 0 & $1 \%$ & 0.07 \\
\hline $32 \%$ & 0.47 & 0 & $32 \%$ & 0.47 \\
\hline $13 \%$ & 0.33 & 0 & $13 \%$ & 0.33 \\
\hline $55 \%$ & 0.50 & 1 & $56 \%$ & 0.50 \\
\hline $32 \%$ & 0.47 & 0 & $32 \%$ & 0.47 \\
\hline $35 \%$ & 0.48 & 0 & $35 \%$ & 0.48 \\
\hline $34 \%$ & 0.47 & 0 & $33 \%$ & 0.47 \\
\hline $32 \%$ & 0.47 & 0 & $32 \%$ & 0.47 \\
\hline $19 \%$ & 0.39 & 0 & $20 \%$ & 0.40 \\
\hline $49 \%$ & 0.50 & 0 & $49 \%$ & 0.50 \\
\hline $84 \%$ & 0.37 & 1 & $84 \%$ & 0.37 \\
\hline $7 \%$ & 0.25 & 0 & $7 \%$ & 0.25 \\
\hline $9 \%$ & 0.29 & 0 & $10 \%$ & 0.30 \\
\hline $32 \%$ & 0.47 & 0 & $32 \%$ & 0.47 \\
\hline $20 \%$ & 0.40 & 0 & $19 \%$ & 0.40 \\
\hline $49 \%$ & 0.50 & 0 & $49 \%$ & 0.50 \\
\hline $43 \%$ & 0.50 & 0 & $43 \%$ & 0.49 \\
\hline $35 \%$ & 0.48 & 0 & $34 \%$ & 0.47 \\
\hline $22 \%$ & 0.41 & 0 & $23 \%$ & 0.42 \\
\hline $32 \%$ & 0.47 & 0 & $32 \%$ & 0.47 \\
\hline
\end{tabular}




\begin{tabular}{|c|c|c|c|c|c|c|}
\hline Received no vitamin A 2 months after delivery & $27 \%$ & 0.44 & 0 & $27 \%$ & 0.44 & 0 \\
\hline Received vitamin A 2 months after delivery & $42 \%$ & 0.49 & 0 & $42 \%$ & 0.49 & 0 \\
\hline $\begin{array}{l}\text { Health Agency } \\
\text { Resp can't get condom or doesn't know where to } \\
\text { get one }\end{array}$ & $92 \%$ & 0.28 & 1 & $91 \%$ & 0.29 & 1 \\
\hline Resp can get a condom & $8 \%$ & 0.28 & 0 & $9 \%$ & 0.29 & 0 \\
\hline $\begin{array}{l}\text { Thinks woman not justified in asking to use } \\
\text { condom if partner has STI or doesn't know }\end{array}$ & $31 \%$ & 0.46 & 0 & $30 \%$ & 0.46 & 0 \\
\hline $\begin{array}{l}\text { Thinks woman is justified in asking for condom } \\
\text { use if partner has STI }\end{array}$ & $69 \%$ & 0.46 & 1 & $70 \%$ & 0.46 & 1 \\
\hline Resp has problem going to treatment alone & $25 \%$ & 0.43 & 0 & $24 \%$ & 0.43 & 0 \\
\hline Resp has no prob going to treatment alone & $75 \%$ & 0.43 & 1 & $76 \%$ & 0.43 & 1 \\
\hline N/A category (missing) & $16 \%$ & 0.36 & 0 & $15 \%$ & 0.36 & 0 \\
\hline Husb/partner/other decides on health treatment & $82 \%$ & 0.38 & 1 & $82 \%$ & 0.38 & 1 \\
\hline Resp alone decides on health treatment & $2 \%$ & 0.15 & 0 & $3 \%$ & 0.16 & 0 \\
\hline $\begin{array}{l}\text { Resp has problem getting permission for health } \\
\text { treatment }\end{array}$ & $20 \%$ & 0.40 & 0 & $20 \%$ & 0.40 & 0 \\
\hline $\begin{array}{l}\text { Resp has no problem getting permission for health } \\
\text { treatment }\end{array}$ & $80 \%$ & 0.40 & 1 & $80 \%$ & 0.40 & 1 \\
\hline \multicolumn{7}{|l|}{ Health Knowledge } \\
\hline Resp never heard of AIDS & $15 \%$ & 0.36 & 0 & $14 \%$ & 0.35 & 0 \\
\hline Resp heard of AIDS & $85 \%$ & 0.36 & 1 & $86 \%$ & 0.35 & 1 \\
\hline N/A category (has not heard of aquatab) & $88 \%$ & 0.32 & 1 & $88 \%$ & 0.32 & 1 \\
\hline Resp doesn't know what aquatab is for & $9 \%$ & 0.28 & 0 & $9 \%$ & 0.28 & 0 \\
\hline Resp knows aquatab used for water purification & $3 \%$ & 0.18 & 0 & $3 \%$ & 0.17 & 0 \\
\hline Resp has not heard of fistula & $56 \%$ & 0.50 & 1 & $56 \%$ & 0.50 & 1 \\
\hline Resp has heard of fistula & $44 \%$ & 0.50 & 0 & $44 \%$ & 0.50 & 0 \\
\hline N/A category (not asked) & $15 \%$ & 0.36 & 0 & $14 \%$ & 0.35 & 0 \\
\hline $\begin{array}{l}\text { Resp doesn't know HIV transmitted during } \\
\text { breastfeeding }\end{array}$ & $32 \%$ & 0.47 & 0 & $32 \%$ & 0.47 & 0 \\
\hline Resp knows HIV transmitted during breastfeeding & $53 \%$ & 0.50 & 1 & $54 \%$ & 0.50 & 1 \\
\hline N/A category & $15 \%$ & 0.36 & 0 & $14 \%$ & 0.35 & 0 \\
\hline $\begin{array}{l}\text { Resp doesn't know HIV transmitted during } \\
\text { delivery }\end{array}$ & $34 \%$ & 0.47 & 0 & $34 \%$ & 0.47 & 0 \\
\hline Resp knows HIV transmitted during delivery & $51 \%$ & 0.50 & 1 & $52 \%$ & 0.50 & 1 \\
\hline N/A category (not asked) & $15 \%$ & 0.36 & 0 & $14 \%$ & 0.35 & 0 \\
\hline $\begin{array}{l}\text { Resp doesn't know HIV transmitted during } \\
\text { pregnancy }\end{array}$ & $33 \%$ & 0.47 & 0 & $34 \%$ & 0.47 & 0 \\
\hline Resp knows HIV transmitted during pregnancy & $52 \%$ & 0.50 & 1 & $52 \%$ & 0.50 & 1 \\
\hline N/A category (not asked) & $15 \%$ & 0.36 & 0 & $14 \%$ & 0.35 & 0 \\
\hline Resp doesn't know where to get an HIV test & $39 \%$ & 0.49 & 0 & $38 \%$ & 0.49 & 0 \\
\hline Resp knows where to get an HIV test & $46 \%$ & 0.50 & 0 & $47 \%$ & 0.50 & 0 \\
\hline N/A category (not asked) & $15 \%$ & 0.36 & 0 & $14 \%$ & 0.35 & 0 \\
\hline \multicolumn{7}{|l|}{ Resp thinks HIV caused by witchcraft or doesn't } \\
\hline know & $25 \%$ & 0.43 & 0 & $24 \%$ & 0.43 & 0 \\
\hline Resp knows HIV not caused by witchcraft & $60 \%$ & 0.49 & 1 & $61 \%$ & 0.49 & 1 \\
\hline Resp never heard of ORS & $10 \%$ & 0.30 & 0 & $10 \%$ & 0.30 & 0 \\
\hline Resp heard of or used ORS & $90 \%$ & 0.30 & 1 & $90 \%$ & 0.30 & 1 \\
\hline Resp never heard of STI & $13 \%$ & 0.33 & 0 & $12 \%$ & 0.33 & 0 \\
\hline Resp heard of STI & $87 \%$ & 0.33 & 1 & $88 \%$ & 0.33 & 1 \\
\hline
\end{tabular}


Cooks indoors with unclean fuel

Cooks with clean fuel our outside living area

Resp has no animal drawn cart

Resp has animal drawn cart

Resp has no car/truck

Resp has car/truck

Resp has no bicycle

Resp has bicycle

HH uses wood, coal, dung or grass for cooking

$\mathrm{HH}$ uses gas, electric, charcoal or cooks outside

No visit to health facility in past 12 months

Visited health facility in past 12 months

Resp not covered by health insurance

Resp covered by health insurance

N/A category (salt not tested)

Iodine below $15 \mathrm{ppm}$ or no salt in $\mathrm{HH}$

Iodine at or above $15 \mathrm{ppm}$ in salt

Resp has no motorcycle

Resp has motorcycle

Resp has no plow

Resp has a plow

Resp didn't sleep under net last night

Resp slept under net last night

N/A category (missing)

Resp washes hands with other method (not soap/water)

Resp washes hands with soap and water

Resp uses some tobacco

Resp uses no tobacco

N/A category (missing)

$\mathrm{HH}$ has unimproved toilet

$\mathrm{HH}$ has improved toilet

N/A category (missing)

$\mathrm{HH}$ has unimproved or toilet shared with other households

HH has improved, not-shared-with-otherhouseholds toilet

No treated mosquito net in home or no net in home

Treated mosquito net in home

Resp has problem with distance to health treatment

Resp has no problem with distance to health

treatment

Resp has problem getting money for health treatment

Resp has no problem getting money for health treatment

Resp has problem with transport to health treatment

Resp has no problem with transport to health treatment

Unimproved and untreated water source

\begin{tabular}{|c|c|c|c|c|}
\hline $4 \%$ & 0.18 & 0 & $3 \%$ & 0.18 \\
\hline $96 \%$ & 0.19 & 1 & $97 \%$ & 0.18 \\
\hline $79 \%$ & 0.40 & 1 & $80 \%$ & 0.40 \\
\hline $21 \%$ & 0.40 & 0 & $20 \%$ & 0.40 \\
\hline $96 \%$ & 0.19 & 1 & $96 \%$ & 0.20 \\
\hline $4 \%$ & 0.19 & 0 & $4 \%$ & 0.20 \\
\hline $88 \%$ & 0.33 & 1 & $87 \%$ & 0.34 \\
\hline $12 \%$ & 0.33 & 0 & $13 \%$ & 0.34 \\
\hline $96 \%$ & 0.19 & 1 & $96 \%$ & 0.20 \\
\hline $4 \%$ & 0.18 & 0 & $4 \%$ & 0.20 \\
\hline $54 \%$ & 0.50 & 1 & $53 \%$ & 0.50 \\
\hline $46 \%$ & 0.50 & 0 & $47 \%$ & 0.50 \\
\hline $97 \%$ & 0.16 & 1 & $97 \%$ & 0.17 \\
\hline $3 \%$ & 0.16 & 0 & $3 \%$ & 0.17 \\
\hline $0 \%$ & 0.02 & 0 & $0 \%$ & 0.02 \\
\hline $79 \%$ & 0.41 & 1 & $79 \%$ & 0.41 \\
\hline $21 \%$ & 0.40 & 0 & $21 \%$ & 0.41 \\
\hline $84 \%$ & 0.37 & 1 & $84 \%$ & 0.37 \\
\hline $16 \%$ & 0.37 & 0 & $16 \%$ & 0.37 \\
\hline $88 \%$ & 0.32 & 1 & $88 \%$ & 0.32 \\
\hline $12 \%$ & 0.32 & 0 & $12 \%$ & 0.32 \\
\hline $76 \%$ & 0.43 & 1 & $75 \%$ & 0.43 \\
\hline $24 \%$ & 0.43 & 0 & $25 \%$ & 0.43 \\
\hline $0 \%$ & 0.07 & 0 & $0 \%$ & 0.07 \\
\hline $48 \%$ & 0.50 & 0 & $48 \%$ & 0.50 \\
\hline $51 \%$ & 0.50 & 1 & $52 \%$ & 0.50 \\
\hline $2 \%$ & 0.15 & 0 & $2 \%$ & 0.15 \\
\hline $98 \%$ & 0.15 & 1 & $98 \%$ & 0.15 \\
\hline $0 \%$ & 0.02 & 0 & $0 \%$ & 0.02 \\
\hline $74 \%$ & 0.44 & 1 & $73 \%$ & 0.45 \\
\hline $26 \%$ & 0.44 & 0 & $27 \%$ & 0.45 \\
\hline $0 \%$ & 0.02 & 0 & $0 \%$ & 0.02 \\
\hline $89 \%$ & 0.32 & 1 & $88 \%$ & 0.33 \\
\hline $11 \%$ & 0.32 & 0 & $12 \%$ & 0.33 \\
\hline $81 \%$ & 0.39 & 1 & $81 \%$ & 0.40 \\
\hline $19 \%$ & 0.39 & 0 & $19 \%$ & 0.40 \\
\hline $41 \%$ & 0.49 & 0 & $41 \%$ & 0.49 \\
\hline $59 \%$ & 0.49 & 1 & $59 \%$ & 0.49 \\
\hline $57 \%$ & 0.49 & 1 & $57 \%$ & 0.50 \\
\hline $43 \%$ & 0.49 & 0 & $43 \%$ & 0.50 \\
\hline $40 \%$ & 0.49 & 0 & $39 \%$ & 0.49 \\
\hline $60 \%$ & 0.49 & 1 & $61 \%$ & 0.49 \\
\hline $25 \%$ & 0.43 & 0 & $24 \%$ & 0.43 \\
\hline
\end{tabular}


Improved and/or treated water source

Resp water source in dwelling/yard

Resp water source located outside household

N/A category (missing)

N/A category (no adult woman in house or missing)

Water fetched by adult women

Water fetched by not adult woman

No water shortage in past 2 weeks

Water shortage in past 2 weeks

$\mathrm{HH}$ doesn't use sanitary water source

HH uses sanitary water source

Adult woman spends 0 hours fetching water

Adult woman spends 1 hour fetching water

Adult woman spends 2 hours fetching water

Adult woman spends 3 hours fetching water

Adult woman spends 4 hours fetching water

N/A category (e.g. doesn't fetch water)

Spends 0 hours fetching water

Spends 1 hour fetching water

Spends 2 hours fetching water

Spends 3 hours fetching water

Spends 4 hours fetching water

N/A category (e.g., doesn't fetch wood)

Spends 0 hours fetching wood

Spends 1 hour fetching wood

Spends 2 hours fetching wood

Spends 3 hours fetching wood

Spends 4 hours fetching wood

Spends 5 hours fetching wood

\section{Institutions}

Resp doesn't have a bank account

Resp has a bank account

Resp doesn't have a computer

Resp has a computer

Resp doesn't have electricity

Resp has electricity

N/A category (not married)

Others involved in resp marriage decision

Resp alone decided on own marriage

Resp never reads newspaper

Resp ever reads newspaper

Resp doesn't have a phone

Resp has a phone

Resp doesn't have a radio

Respondent has a radio

Resp never listens to radio

Resp ever listens to radio

Resp doesn't have a TV

Resp has a TV

\begin{tabular}{|c|c|c|c|c|}
\hline $75 \%$ & 0.43 & 1 & $76 \%$ & 0.43 \\
\hline $12 \%$ & 0.33 & 0 & $13 \%$ & 0.34 \\
\hline $87 \%$ & 0.34 & 1 & $85 \%$ & 0.35 \\
\hline $1 \%$ & 0.11 & 0 & $1 \%$ & 0.11 \\
\hline $13 \%$ & 0.34 & 0 & $15 \%$ & 0.35 \\
\hline $55 \%$ & 0.50 & 1 & $55 \%$ & 0.50 \\
\hline $31 \%$ & 0.46 & 0 & $31 \%$ & 0.46 \\
\hline $76 \%$ & 0.43 & 1 & $76 \%$ & 0.43 \\
\hline $24 \%$ & 0.43 & 0 & $24 \%$ & 0.43 \\
\hline $31 \%$ & 0.46 & 0 & $31 \%$ & 0.46 \\
\hline $69 \%$ & 0.46 & 1 & $69 \%$ & 0.46 \\
\hline $45 \%$ & 0.50 & 0 & $45 \%$ & 0.50 \\
\hline $48 \%$ & 0.50 & 0 & $48 \%$ & 0.50 \\
\hline $5 \%$ & 0.21 & 0 & $4 \%$ & 0.20 \\
\hline $1 \%$ & 0.12 & 0 & $1 \%$ & 0.11 \\
\hline $1 \%$ & 0.08 & 0 & $1 \%$ & 0.09 \\
\hline $2 \%$ & 0.14 & 0 & $2 \%$ & 0.13 \\
\hline $16 \%$ & 0.37 & 0 & $17 \%$ & 0.38 \\
\hline $70 \%$ & 0.46 & 1 & $70 \%$ & 0.46 \\
\hline $8 \%$ & 0.27 & 0 & $8 \%$ & 0.27 \\
\hline $2 \%$ & 0.14 & 0 & $2 \%$ & 0.14 \\
\hline $1 \%$ & 0.11 & 0 & $1 \%$ & 0.11 \\
\hline $16 \%$ & 0.37 & 0 & $16 \%$ & 0.37 \\
\hline $3 \%$ & 0.16 & 0 & $2 \%$ & 0.15 \\
\hline $52 \%$ & 0.50 & 1 & $53 \%$ & 0.50 \\
\hline $18 \%$ & 0.38 & 0 & $17 \%$ & 0.38 \\
\hline $8 \%$ & 0.27 & 0 & $8 \%$ & 0.27 \\
\hline $2 \%$ & 0.15 & 0 & $2 \%$ & 0.15 \\
\hline $1 \%$ & 0.11 & 0 & $1 \%$ & 0.11 \\
\hline $94 \%$ & 0.23 & 1 & $94 \%$ & 0.24 \\
\hline $6 \%$ & 0.23 & 0 & $6 \%$ & 0.24 \\
\hline $98 \%$ & 0.15 & 1 & $97 \%$ & 0.16 \\
\hline $2 \%$ & 0.15 & 0 & $3 \%$ & 0.16 \\
\hline $77 \%$ & 0.42 & 1 & $76 \%$ & 0.43 \\
\hline $23 \%$ & 0.42 & 0 & $24 \%$ & 0.43 \\
\hline $31 \%$ & 0.46 & 0 & $31 \%$ & 0.46 \\
\hline $52 \%$ & 0.50 & 1 & $52 \%$ & 0.50 \\
\hline $17 \%$ & 0.37 & 0 & $17 \%$ & 0.38 \\
\hline $95 \%$ & 0.23 & 1 & $94 \%$ & 0.23 \\
\hline $5 \%$ & 0.23 & 0 & $6 \%$ & 0.23 \\
\hline $38 \%$ & 0.49 & 0 & $37 \%$ & 0.48 \\
\hline $62 \%$ & 0.49 & 1 & $63 \%$ & 0.48 \\
\hline $42 \%$ & 0.49 & 0 & $41 \%$ & 0.49 \\
\hline $58 \%$ & 0.49 & 1 & $59 \%$ & 0.49 \\
\hline $39 \%$ & 0.49 & 0 & $38 \%$ & 0.49 \\
\hline $61 \%$ & 0.49 & 1 & $62 \%$ & 0.49 \\
\hline $81 \%$ & 0.39 & 1 & $80 \%$ & 0.40 \\
\hline $19 \%$ & 0.39 & 0 & $20 \%$ & 0.40 \\
\hline
\end{tabular}


Resp never watches tv

Resp ever watches TV

Generally: Beating sometimes justified or doesn't know

Generally: Never justified in beating wife

N/A category (not married)

Resp decides jointly or others decide on visiting family/relatives

Resp alone decides on visiting family/relatives

N/A category (not married)

First pregnancy occurred before marriage

First pregnancy occurred after marriage

\begin{tabular}{rrr|rrr}
$70 \%$ & 0.46 & 1 & $69 \%$ & 0.46 & 1 \\
$30 \%$ & 0.46 & 0 & $31 \%$ & 0.46 & 0 \\
$59 \%$ & 0.49 & 1 & $59 \%$ & 0.49 & 1 \\
$41 \%$ & 0.49 & 0 & $41 \%$ & 0.49 & 0 \\
$16 \%$ & 0.36 & 0 & $15 \%$ & 0.36 & 0 \\
$77 \%$ & 0.42 & 1 & $78 \%$ & 0.42 & 1 \\
$7 \%$ & 0.26 & 0 & $7 \%$ & 0.26 & 0 \\
$19 \%$ & 0.39 & 0 & $18 \%$ & 0.39 & 0 \\
$20 \%$ & 0.40 & 0 & $20 \%$ & 0.40 & 0 \\
$61 \%$ & 0.49 & 1 & $61 \%$ & 0.49 & 1 \\
\hline
\end{tabular}


Appendix 2: Women's Empowerment in Nutrition Grid

Table A2.1: A general WEN Grid with candidate indicators for each domain-dimension (adapted from Authors, 2017)

\begin{tabular}{|c|c|c|c|c|c|}
\hline & \multicolumn{5}{|c|}{ DIMENSIONS } \\
\hline & $\begin{array}{l}\text { Knowledge } \\
\text { (To have knowledge } \\
\text { of...) }\end{array}$ & $\begin{array}{l}\text { Resources } \\
\text { (Material and social resources, structural conditions } \\
\text { /norms) }\end{array}$ & $\begin{array}{l}\text { Agency } \\
\text { (Executive \& } \\
\text { Implementation) }\end{array}$ & $\begin{array}{l}\text { Intermediate } \\
\text { Achievements }\end{array}$ & $\begin{array}{l}\text { Ultimate } \\
\text { Achievem } \\
\text { ents }\end{array}$ \\
\hline 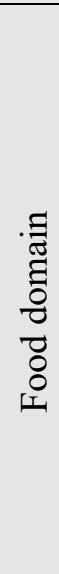 & $\begin{array}{l}\text { Knowledge of } \\
\text { 1. Nutrition } \\
\text { 2. Special diets } \\
\text { 3. Government } \\
\text { schemes (for self- } \\
\text { employed, trainings, } \\
\text { farming) }\end{array}$ & $\begin{array}{l}\text { 1. Access to paid work with adequate remuneration } \\
\text { 2. Opportunities for work throughout the year } \\
\text { (Private/government/ NGOs) } \\
\text { 3. Opportunities for self-employment (capital/credit, market, } \\
\text { Livestock holdings, land size, forest access, training) } \\
\text { 4. Access to food (Market purchases, Production, State } \\
\text { schemes, CPR NGOs/Civil society Org/SHGs) } \\
\text { 5. Norms around consumption } \\
\text { (a)Eating order } \\
\text { (b)Fasting } \\
\text { (c)Taboos (vegetarianism, milk avoidance) } \\
\text { 6. Time available (to do paid work, or collect and prepare } \\
\text { food) }\end{array}$ & $\begin{array}{l}\text { 1. Decisions around } \\
\text { (a) Food production } \\
\text { (b) Procurement } \\
\text { (c) Preparation } \\
\text { (d) Distribution } \\
\text { 2. Control over income } \\
\text { and expenditure on food } \\
\text { budgets and types of food }\end{array}$ & $\begin{array}{l}\text { 1. Food } \\
\text { Adequacy } \\
\text { (individual) } \\
\text { 2. Coping } \\
\text { strategies } \\
\text { Index } \\
\text { 3. Dietary } \\
\text { Diversity } \\
\text { (individual) }\end{array}$ & $\begin{array}{l}\text { BMI } \\
\text { MUAC } \\
\text { Anaemia }\end{array}$ \\
\hline
\end{tabular}




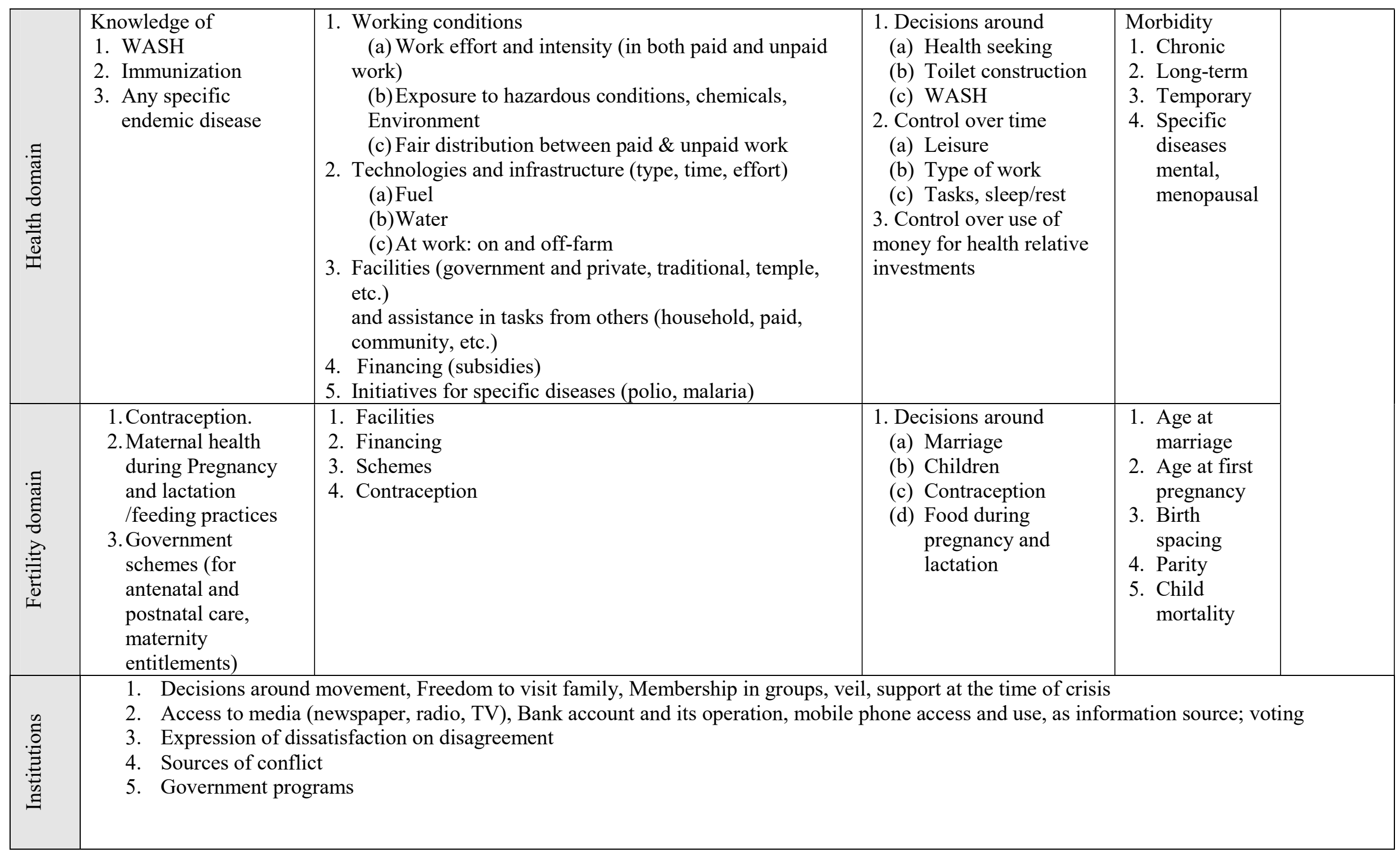




\section{Appendix 3: Robustness Checks}

Figure A3.1: Correlation between linear probability model and logistic regression for anemia
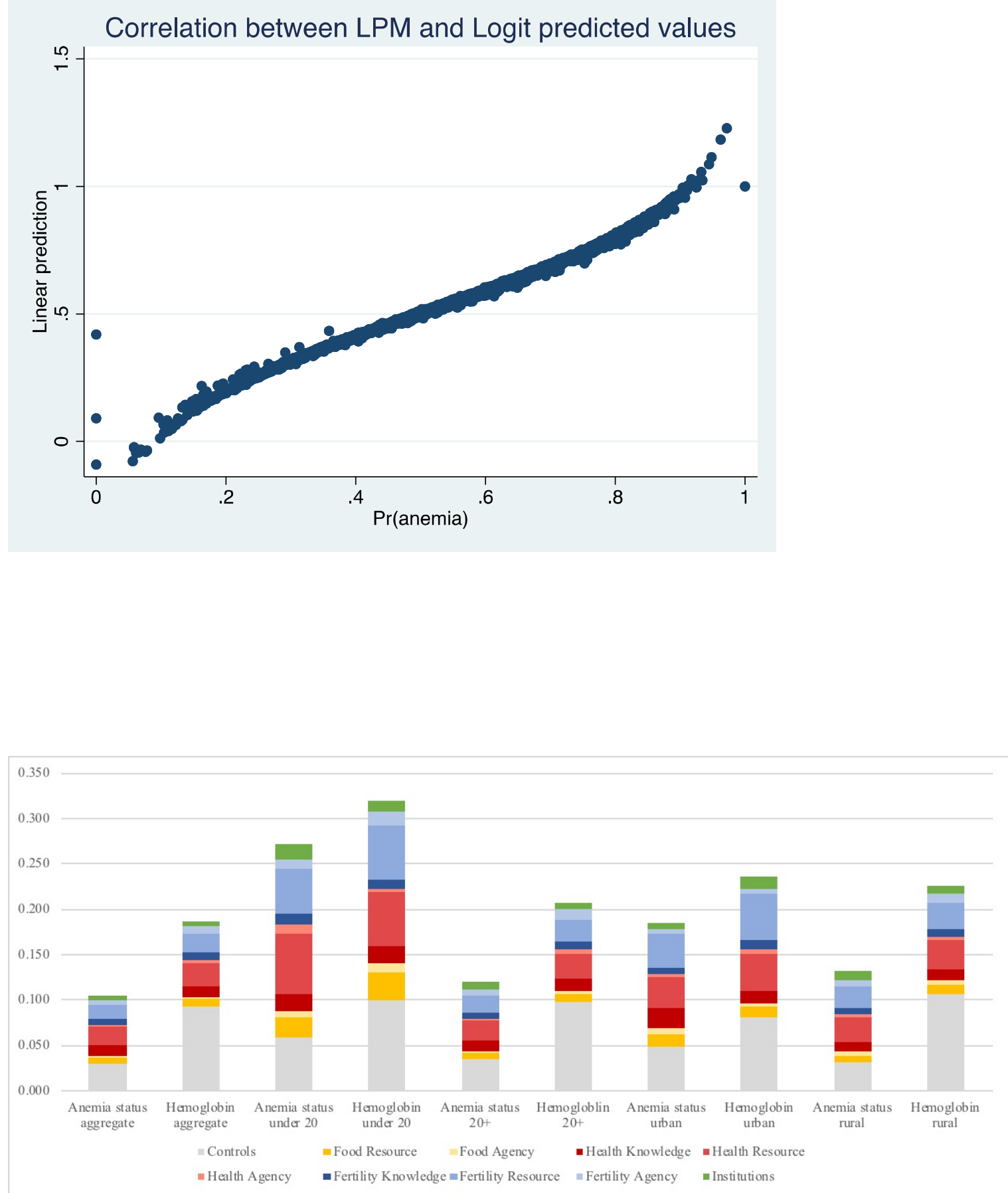

Figure A3.2: Shapley-Owen estimation results using continuous measure of hemoglobin 


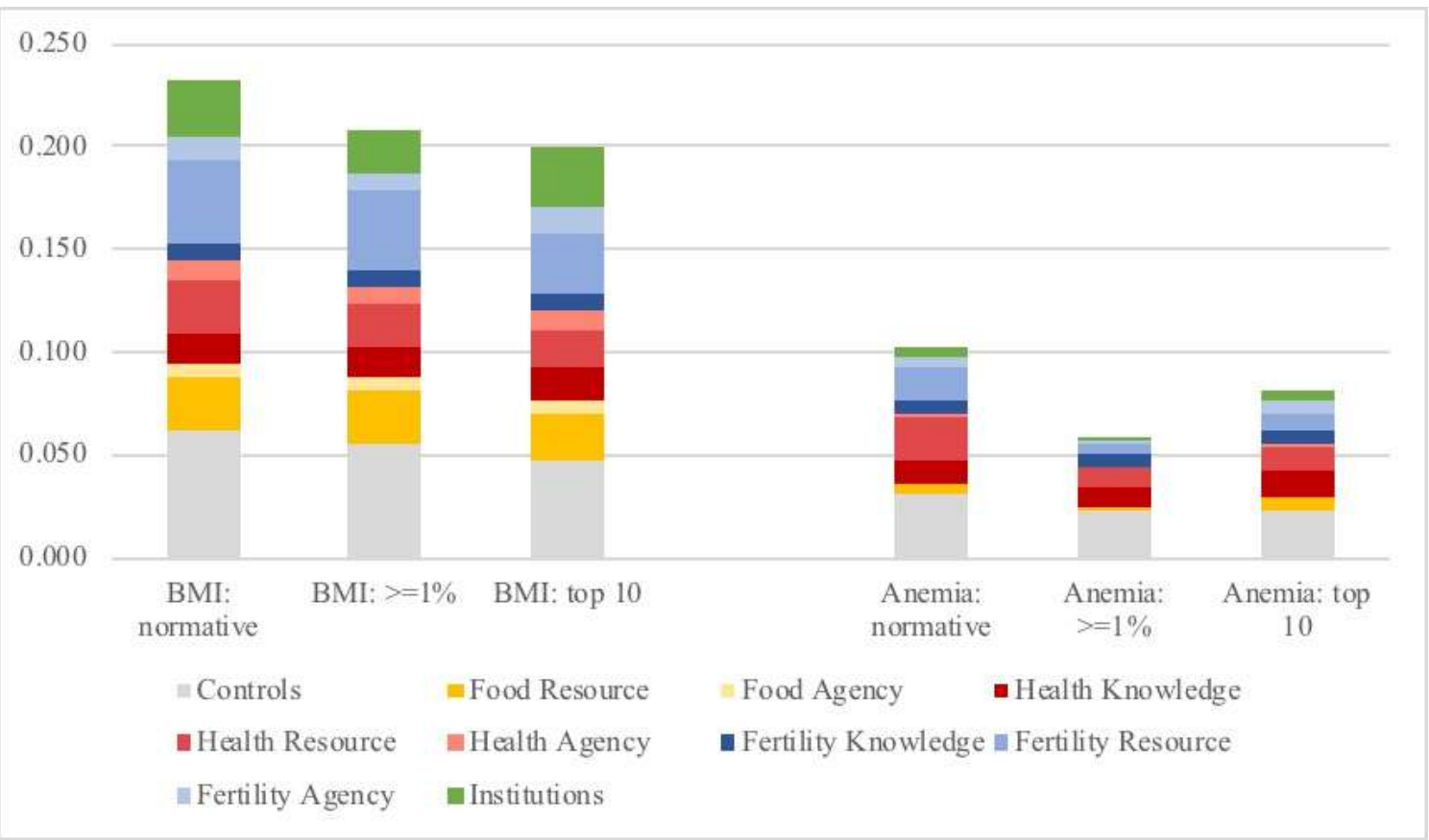

Figure A3.3: Comparing results using normative approach to selecting indictors and two datadriven approaches to selection indicators, one using indicators with high Shapley-Owen values $(>=1 \%)$ and one using the ten most important indicators in each domain-dimension.

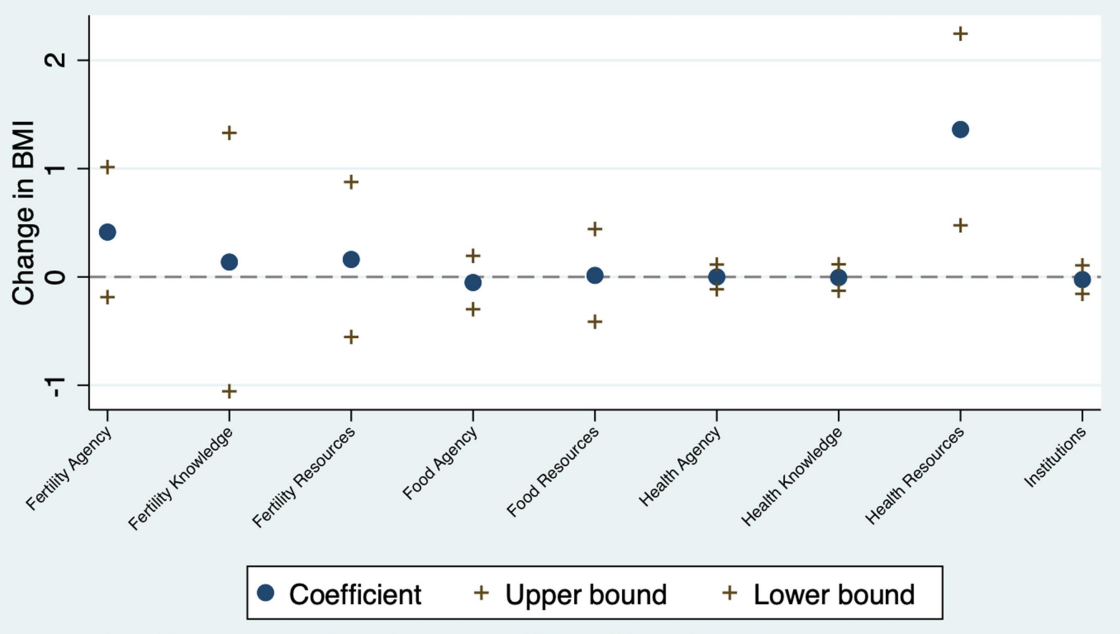

Note: Upper and lower bounds represent $95 \%$ confidence intervals.

Figure A3.4: Joint effects of 1 standard deviation increase in each domain dimension on BMI 


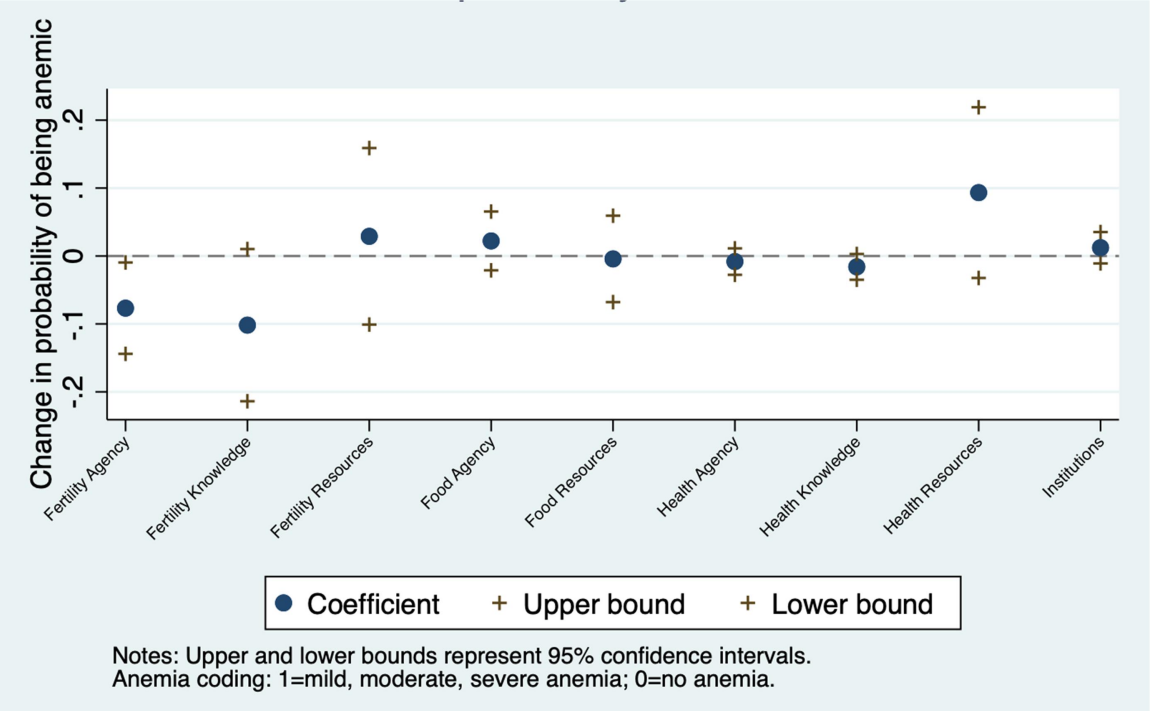

Figure A3.5: Joint effects of 1 standard deviation increase in each domain dimension on Anemia

Table A3.1 Joint effects of 1 standard deviation increase in each domain-dimension

\begin{tabular}{lllllllll} 
& \multicolumn{4}{c}{ BMI } & \multicolumn{3}{c}{ Anemia } \\
\hline & \multicolumn{3}{c}{ Coefficient } & \multicolumn{1}{c}{ p- } & \multicolumn{2}{c}{$95 \%$ Confidence } & \multicolumn{3}{c}{ p- } & \multicolumn{2}{c}{$95 \%$ Confidence } \\
& value & \multicolumn{2}{c}{ Interval } & Coefficient & value & Interval \\
\hline Fertility Agency & 0.414 & 0.176 & -0.186 & 1.014 & -0.077 & 0.025 & -0.144 & -0.010 \\
Fertility Knowledge & 0.137 & 0.822 & -1.056 & 1.330 & -0.102 & 0.075 & -0.214 & 0.010 \\
Fertility Resources & 0.161 & 0.658 & -0.554 & 0.876 & 0.029 & 0.661 & -0.101 & 0.159 \\
Food Agency & -0.052 & 0.681 & -0.298 & 0.195 & 0.022 & 0.315 & -0.021 & 0.065 \\
Food Resources & 0.014 & 0.948 & -0.414 & 0.442 & -0.004 & 0.896 & -0.068 & 0.059 \\
Health Agency & 0.000 & 0.998 & -0.114 & 0.114 & -0.008 & 0.411 & -0.028 & 0.011 \\
Health Knowledge & -0.006 & 0.930 & -0.128 & 0.117 & -0.016 & 0.099 & -0.035 & 0.003 \\
Health Resources & 1.361 & 0.003 & 0.477 & 2.246 & 0.093 & 0.145 & -0.032 & 0.219 \\
Institutions & -0.025 & 0.713 & -0.156 & 0.107 & 0.012 & 0.300 & -0.011 & 0.035 \\
\hline
\end{tabular}

